\title{
Comparison of three vertically resolved ozone data sets: climatology, trends and radiative forcings
}

\author{
B. Hassler ${ }^{1,2}$, P. J. Young ${ }^{1,2, *}$, R. W. Portmann ${ }^{2}$, G. E. Bodeker ${ }^{3}$, J. S. Daniel ${ }^{2}$, K. H. Rosenlof ${ }^{2}$, and S. Solomon ${ }^{4}$ \\ ${ }^{1}$ Cooperative Institute for Research in Environmental Sciences (CIRES), University of Colorado at Boulder, Boulder, \\ Colorado, USA \\ ${ }^{2}$ NOAA, Earth System Research Laboratory, Chemical Sciences Division, Boulder, Colorado, USA \\ ${ }^{3}$ Bodeker Scientific, Alexandra, Central Otago, New Zealand \\ ${ }^{4}$ Department of Earth, Atmospheric, and Planetary Sciences, Massachusetts Institute of Technology, Cambridge, \\ Massachusetts, USA \\ *now at: Lancaster Environment Centre, Lancaster University, Lancaster, UK \\ Correspondence to: B. Hassler (birgit.hassler@noaa.gov)
}

Received: 31 July 2012 - Published in Atmos. Chem. Phys. Discuss.: 9 October 2012

Revised: 28 March 2013 - Accepted: 4 May 2013 - Published: 6 June 2013

\begin{abstract}
Climate models that do not simulate changes in stratospheric ozone concentrations require the prescription of ozone fields to accurately calculate UV fluxes and stratospheric heating rates. In this study, three different global ozone time series that are available for this purpose are compared: the data set of Randel and Wu (2007) (RW07), Cionni et al. (2011) (SPARC), and Bodeker et al. (2013) (BDBP). All three data sets represent multiple-linear regression fits to vertically resolved ozone observations, resulting in a spatially and temporally continuous stratospheric ozone field covering at least the period from 1979 to 2005 . The main differences among the data sets result from regression models, which use different observations and include different basis functions. The data sets are compared against ozonesonde and satellite observations to assess how the data sets represent concentrations, trends and interannual variability. In the Southern Hemisphere polar region, RW07 and SPARC underestimate the ozone depletion in spring ozonesonde measurements. A piecewise linear trend regression is performed to estimate the 1979-1996 ozone decrease globally, covering a period of extreme depletion in most regions. BDBP overestimates Arctic and tropical ozone depletion over this period relative to the available measurements, whereas the depletion is underestimated in RW07 and SPARC. While the three data sets yield ozone concentrations that are within a range of different observations, there is a large spread in their respective ozone trends. One consequence of this is differences of almost a factor of four in the calculated stratospheric ozone ra-
\end{abstract}

diative forcing between the data sets (RW07: $-0.038 \mathrm{Wm}^{-2}$, SPARC: $-0.033 \mathrm{Wm}^{-2}$, BDBP: $\left.-0.119 \mathrm{Wm}^{-2}\right)$, important in assessing the contribution of stratospheric ozone depletion to the total anthropogenic radiative forcing.

\section{Introduction}

Using a realistic representation of the stratospheric ozone distribution and its changes over time in a changing climate is important not only for quantifying the flux of harmful UV radiation from the sun reaching the earth's surface, but also to understand changes in the dynamics and energy budget of the earth's atmosphere. Capturing the observed stratospheric ozone depletion in global climate models is crucial for reproducing stratospheric temperature changes (Dall' Amico et al., 2010), Southern Hemisphere (SH) tropospheric circulation changes (Son et al., 2009; Polvani et al., 2011), climate and surface temperatures in Antarctica (Gillett and Thompson, 2003), global tropospheric temperature changes (Dall' Amico et al., 2009) and global precipitation changes (Purich and Son, 2012).

Global climate models that do not include interactive chemistry depend on a prescribed ozone field as input to incorporate these effects of ozone on the climate system. The differences in modelled climate responses arising from different input ozone fields can be significant, and can complicate the identification of sources of climate signal uncertainty 
(e.g. Miller et al., 2006; Solomon et al., 2012). Furthermore, a data set is necessary to validate global chemistry-climate models, where ozone concentrations are calculated as part of the simulation. Therefore, a realistic ozone data set is important both for reducing the uncertainty in the climate model output, and for validation purposes.

Although many different measurement systems provide ozone measurements with high vertical resolution (multiple satellite instruments, ozonesondes, ozone lidars, etc.), no single measurement type has the temporal and spatial coverage required to create a global, zonal mean, spatially and temporally continuous (gap-free) stratospheric ozone data set. In particular, the tropics and the high latitudes are regions where long-term coverage is especially limited. Because a data set with incomplete coverage is not suitable as a boundary condition for climate models, approaches have been designed to combine different kinds of observations and to fill any remaining gaps.

This study focuses on three ozone data sets that (i) have high vertical resolution, (ii) cover the entire globe throughout the period from at least 1979-2005, and (iii) have been mainly created to provide climate models with a realistic ozone input. All three data sets are created by using multiple linear regression fits to a selected set of observations, and therefore are not identical to the original raw measurements. A comparison between these fitted data sets and direct measurements is necessary to understand their strengths and weaknesses.

This study is organised as follows. In Sect. 2, the three ozone data sets are characterized and briefly described. We consider how well the data sets capture the observed interannual ozone variability in Sect. 3 , comparing the vertically integrated (ozone column) and vertically resolved climatologies against TOMS/SBUV (Total Ozone Mapping Spectrometer/Solar Backscatter UltraViolet instrument) and SBUV/2 data. Section 4 discusses the climatological anomalies of the data sets. Time series from the regression-based data sets for selected months, pressure levels, and latitude zones are compared against corresponding individual data points from several measurement systems in Sect. 5. We discuss trends in the data sets in Sect. 6, focussing on the ozone change from 1979 to 1996, a period of extreme depletion in many regions. The purpose of this is to assess the extent to which the data sets capture the observed ozone decreases, although we emphasize that the data sets are not suitable for assessing the true ozone trend as they are all based on regression model output and any trends are effectively imposed by the fit to a linear trend or EESC basis function in the regression model. The differences in the three ozone data sets result in differences in global radiative forcing, which are discussed in Sect. 7. Finally, in Sect. 8, measures of the overall agreement between the three data sets and direct measurements from the Stratospheric Aerosol and Gas Experiment II (SAGE II) and ozonesondes are presented.

\section{Brief description of the ozone data sets}

Three different ozone data sets are considered in this study, all consisting of a regression model fit to observational data. The differences between the data sets arise mainly from (i) different basis functions used for the multiple linear regression fit to the observations, (ii) the use of different observational data to which the regression models are applied, and (iii) inclusion (or not) of the troposphere. A brief description of each data set follows, and an overview is provided in Table 1.

\subsection{Randel and Wu (RW07)}

This ozone data set is described by Randel and Wu (2007). The observational data to which their regression model fit was applied are derived from SAGE I and II measurements (McCormick et al., 1989), covering $\sim 55^{\circ} \mathrm{S}$ to $55^{\circ} \mathrm{N}$ and the polar regions above $30 \mathrm{hPa}$. Measurements from SAGE I are not used below $20 \mathrm{~km}$. Ozonesonde data from Syowa $\left(69^{\circ} \mathrm{S}\right)$ and Resolute $\left(75^{\circ} \mathrm{N}\right)$ provide data for the polar regions from a climatological tropopause up to $30 \mathrm{hPa}$. These ozonesonde stations both lie on the edges of their respective polar vortices, and hence may underestimate the maximum depletion (e.g. see the comparison of Syowa and South Pole data by Solomon et al., 2005). Between $55^{\circ} \mathrm{S}$ and $55^{\circ} \mathrm{N}$, the deseasonalized data are fitted with a regression model consisting of an equivalent effective stratospheric chlorine (EESC; Daniel et al., 1995) basis function; a solar activity proxy, namely the F10.7 $\mathrm{cm}$ radio flux (used only above $20 \mathrm{~km}$ ); and two orthogonal basis functions representing the quasi-biennial oscillation (QBO). The deseasonalized ozonesonde data are fitted in the polar regions only with the EESC basis function, and the regression coefficients obtained are applied at all latitudes poleward of $65^{\circ}$. Ozonesonde trends and SAGE trends are then merged by interpolation between $55^{\circ}$ and $65^{\circ}$. The output from the regression model therefore represents only ozone anomalies. These anomalies are then superimposed on the ozone climatology of Fortuin and Kelder (1998) (hereafter FK98) to provide a global ozone data set. FK98 use ozonesonde data from 30 stations and measurements from SBUV/SBUV2 from 1980 to 1991 to create a monthly zonal mean, vertically resolved climatology. The SBUV/SBUV2 observations have a relatively low vertical resolution (about $5 \mathrm{~km}$ ). This climatology extends from the surface to $0.3 \mathrm{hPa}$ on 19 pressure levels, but the RW07 data set only uses the stratospheric levels.

RW07 spans the period from 1979 to 2005 , and extends from the surface to $50 \mathrm{~km}$ with a vertical resolution of $1 \mathrm{~km}$. Since the RW07 data set is provided on an altitude grid and in ozone units of DU/km, here it has been converted onto pressure levels and into volume mixing ratio units (parts per million volume, ppmv) to facilitate comparisons with the other two data sets. The US standard atmosphere was used for the conversion (see the Supplement). 
Table 1. Overview of the characteristics of the three different data sets and information about the basis functions (BF) included in the regression model that was used to create the data sets.

\begin{tabular}{|c|c|c|c|}
\hline & RW07 & SPARC & BDBP \\
\hline Ozone units & $\mathrm{DU} \mathrm{km}^{-1}$ & ppmv & $\begin{array}{c}\text { ppmv } \\
\text { molecules } \mathrm{m}^{-3}\end{array}$ \\
\hline Vertical units & $\mathrm{km}$ & $\mathrm{hPa}$ & $\begin{array}{l}\mathrm{km} \\
\mathrm{hPa}\end{array}$ \\
\hline Temporal resolution & monthly & monthly & monthly \\
\hline Zonal bands & $\begin{array}{l}90^{\circ} \mathrm{S}-90^{\circ} \mathrm{N}, \\
5^{\circ} \text { zones }(37)\end{array}$ & $\begin{array}{l}90^{\circ} \mathrm{S}-90^{\circ} \mathrm{N}, \\
5^{\circ} \text { zones }(37)\end{array}$ & $\begin{array}{c}87.5^{\circ} \mathrm{S}-87.5^{\circ} \mathrm{N} \\
5^{\circ} \text { zones }(36)\end{array}$ \\
\hline Number of vertical levels & 50 & 24 & 70 \\
\hline Highest pressure level & $0.81 \mathrm{hPa}^{*}$ & $1.0 \mathrm{hPa}$ & $0.046 \mathrm{hPa}$ \\
\hline Time period covered & 01/1979-12/2005 & 01/1979-12/2010 & $01 / 1979-12 / 2006$ \\
\hline Includes troposphere & - & $\checkmark$ & $\checkmark$ \\
\hline Includes stratosphere & $\checkmark$ & $\checkmark$ & $\checkmark$ \\
\hline Linear Trend BF & - & - & $\checkmark$ \\
\hline EESC BF & $\checkmark$ & $\checkmark$ & $\checkmark$ \\
\hline QBO BF (2 orthog.) & $\checkmark$ & - & $\checkmark$ \\
\hline Solar cycle BF & $\checkmark$ & $\checkmark$ & $\checkmark$ \\
\hline Volcano BF & - & - & $\checkmark$ \\
\hline ENSO BF & - & - & $\checkmark$ \\
\hline
\end{tabular}

* if converted with the US standard atmosphere.

\subsection{SPARC}

The SPARC ozone data set is described by Cionni et al. (2011) and was developed by the Atmospheric Chemistry $\&$ Climate (AC\&C) initiative, a joint Stratospheric Processes and their Role in Climate (SPARC) and International Global Atmospheric Chemistry (IGAC) activity. The data set consists of merged chemistry-climate model and observationally based regression model output, spanning from 1850 to 2100, and was developed in support of the climate model integrations conducted as part of the 5th Coupled Model Intercomparison Project (CMIP5) for the Intergovernmental Panel on Climate Change (IPCC) 5th Assessment Report (AR5) (Taylor et al., 2012). In this study we focus on the post 1979 , observationally based part of the data set. For this period, the SPARC ozone data set is very similar to RW07, except that the QBO basis functions were omitted from the regression model, which leads to less variability in the data set. As for RW07, the ozone anomalies derived from the regression model are superimposed on the FK98 ozone climatology to provide complete coverage for the observationally based part of the SPARC data set. In contrast to RW07, SPARC also includes data for the troposphere, taken from chemistryclimate model simulations and merged with the stratospheric data across a climatological tropopause.

The observationally based part of the SPARC data set extends from 1979 to 2009, and has a vertical range from the surface to $1 \mathrm{hPa}$ on 24 pressure levels.

\subsection{BDBP}

The BDBP data set is fully described by Bodeker et al. (2013). The data set is based on a regression model fit to the observational ozone data from Hassler et al. (2008), incorporating measurements from SAGE I and II, the Halogen Occultation Experiment (HALOE) instrument, the Polar Ozone and Aerosol Measurement (POAM) II and III instruments, the Limb Infrared Monitor of the Stratosphere (LIMS), the Improved Limb Array Spectrometer (ILAS and ILAS II), and over 130 ozonesonde stations globally, representing substantially more data sources than used in either the RW07 or SPARC data sets. In addition, the regression model used to fit the data contains several more basis functions than the other data sets (see Table 1), incorporating a linear trend, EESC, the QBO (two basis functions), El NiñoSouthern Oscillation, the volcanic eruption of Mt Pinatubo (1991), and solar activity (F10.7 $\mathrm{cm}$ radio flux). Other versions of the BDBP are available that use fewer basis functions (see Bodeker et al., 2013). The regression model is used both for determining interannual ozone variability and for describing the underlying annual cycle, whereas the regression models used for the RW07 and SPARC data sets were applied to deseasonalized data. Also in contrast to RW07 and SPARC, the regression model was also used to calculate gapfree ozone fields in the troposphere.

The BDBP data set extends from 1979 to 2006, and from the surface to $\sim 0.05 \mathrm{hPa}(70 \mathrm{~km})$ in the vertical on 70 levels spaced $\sim 1 \mathrm{~km}$ apart. BDBP is available in both a pressure and altitude coordinate system, and includes both ozone volume mixing ratio and ozone number density. 

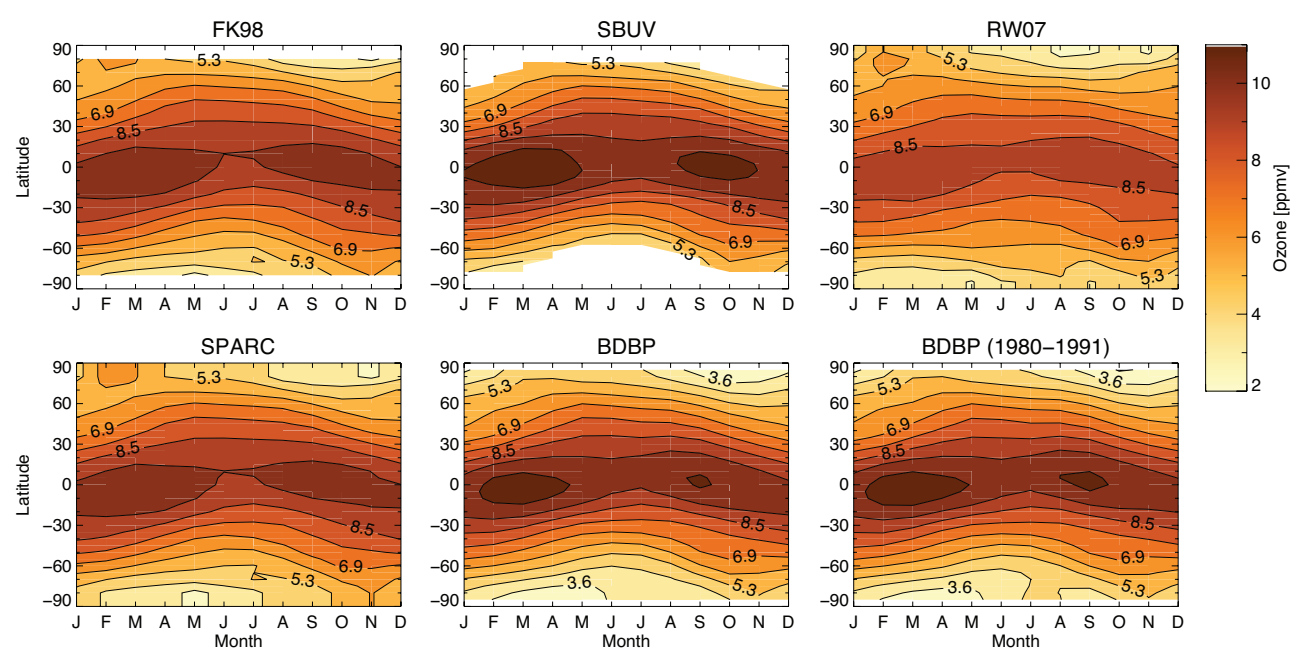

Fig. 1. Ozone climatologies at $10 \mathrm{hPa}$ as a function of latitude and month, for the Fortuin \& Kelder climatology (FK98), a climatology derived from SBUV measurements (period 1979 to 2005; SBUV), for the three different data sets (RW07, SPARC and BDBP) calculated for the period 1979 to 2005, and for the BDBP data set calculated for the shorter period 1980 to 1991 (BDBP (1980-1991)). Dark orange/brown represent high ozone values, light orange represent low ozone values.

\section{Climatologies}

\subsection{Ozone at $10 \mathrm{hPa}$}

For all three data sets, climatologies at key pressure levels were calculated for a common period chosen to be from 1979 to 2005 . Figure 1 shows the climatologies for $10 \mathrm{hPa}$ for the data sets as compared to the FK98 climatology and the observations from SBUV/2 (Stolarski and Frith, 2006). Note that the SBUV data has a coarser vertical resolution than RW07 and BDBP, and the measurements registered at $10 \mathrm{hPa}$ include information from pressure levels above and below $10 \mathrm{hPa}$ due to the averaging kernel. In addition, Fig. 1 shows the BDBP climatology for the years 1980 to 1991, i.e. covering the same period as the FK98 climatology.

The overall structure is very similar between the three data sets, the FK98 climatology and the SBUV data, notably (i) the low ozone in the tropics with a weak annual cycle maximizing in February/March and again in September/October; (ii) an almost latitudinally symmetric gradient from the high tropical ozone to lower high-latitude ozone; and (iii) slightly higher values in the polar regions in late winter/early spring (Northern Hemisphere (NH): February/March; SH: October/November).

Since both the RW07 and SPARC data sets use the ozone climatology described by FK98, their climatologies should be almost identical. While SPARC and FK98 indeed show almost an identical ozone distribution at $10 \mathrm{hPa}$, the RW07 climatology shows lower ozone than FK98 (and SPARC and BDBP) in the tropics, but similar ozone for the high latitudes. The differences between the RW07 and FK98 climatologies could be due to their different vertical resolutions. The FK98 climatology consists of 19 levels extending from
$1000 \mathrm{hPa}$ to $0.3 \mathrm{hPa}$, whereas the RW07 data set has 50 levels that range from the surface to about $0.8 \mathrm{hPa}$, and that were converted onto pressure levels with a standard atmosphere (see Table 1). The interpolation of the climatology onto the more highly resolved RW07 vertical levels may introduce a slight bias in the calculated pressure, with subsequent impacts on the conversion from DU/km to volume mixing ratio. In contrast, the SPARC data set has 24 levels that extend from $1000 \mathrm{hPa}$ to $1 \mathrm{hPa}$, which is closer to the levels provided by the FK98 data set.

The BDBP climatology shows the highest ozone in the tropics at $10 \mathrm{hPa}$ of all three data sets, closely matching the peak concentrations in the SBUV climatology. The gradient in ozone between the tropics and the mid-latitudes is steepest for BDBP, with that data set showing the lowest $10 \mathrm{hPa}$ polar ozone concentrations of all three data sets. This feature agrees well with the SBUV climatology, for the areas where data is available. The 1980-1991 BDBP climatology is similar to that calculated for 1979-2005, with slightly increased ozone concentrations due to the lower levels of ozone depleting substances for 1980-1991 compared to 1979 to 2005 .

Climatologies for levels lower in the atmosphere show similar patterns to the $10 \mathrm{hPa}$ climatologies, with a pattern of low ozone appearing in the high-latitude spring months at levels below $50 \mathrm{hPa}$. Due to the use of the FK98 climatology in the construction of SPARC and RW07, differences between these data sets might be expected to be negligible. In the case of SPARC, the differences are indeed small and are likely attributable to the interpolation to different pressure levels and the higher resolution latitude grid. In contrast, there are more pronounced differences between the RW07 and FK98 climatologies, with ozone values being higher for RW07 from the lower stratosphere up to $50 \mathrm{hPa}$, at all 
$90^{\circ} \mathrm{S}$ to $70^{\circ} \mathrm{S}$
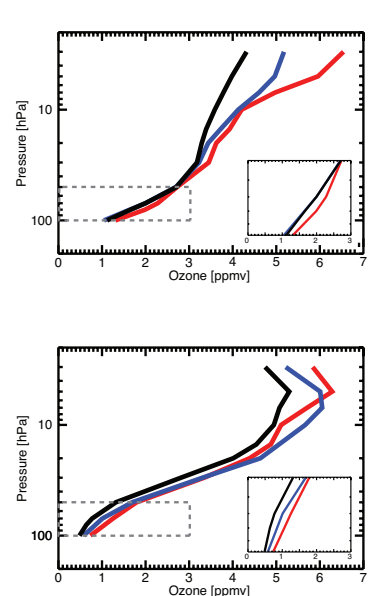

$55^{\circ} \mathrm{S}$ to $40^{\circ} \mathrm{S}$
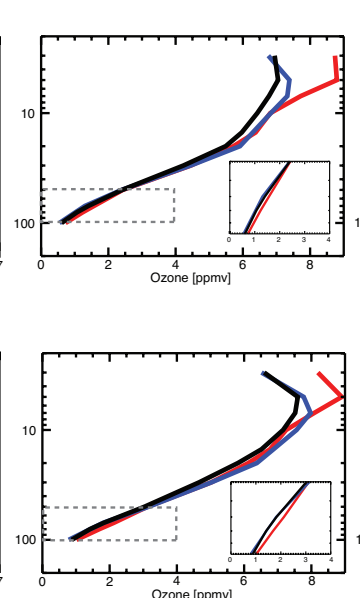

$20^{\circ} \mathrm{S}$ to $20^{\circ} \mathrm{N}$

MAM

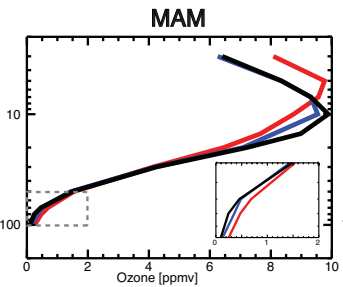

SON

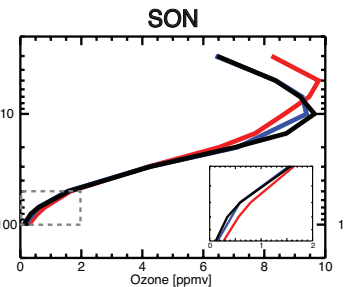

$40^{\circ} \mathrm{N}$ to $55^{\circ} \mathrm{N}$
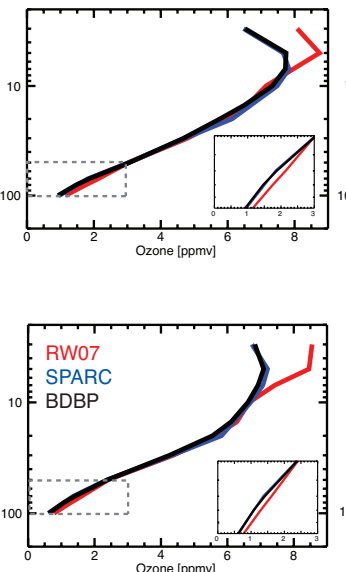

$70^{\circ} \mathrm{N}$ to $90^{\circ} \mathrm{N}$
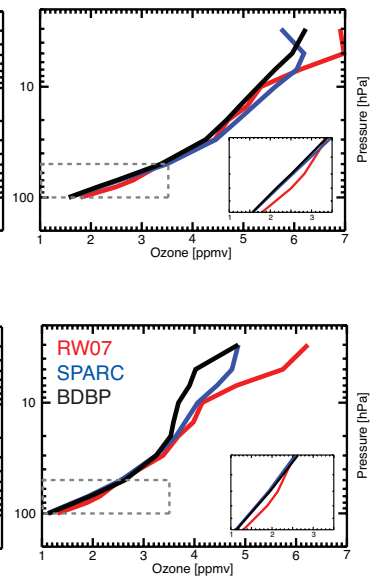

Fig. 2. Climatological ozone profiles from the three ozone data sets for five latitude regions (first column: $90^{\circ} \mathrm{S}$ to $70^{\circ} \mathrm{S}$, second column: $55^{\circ} \mathrm{S}$ to $40^{\circ} \mathrm{S}$, third column: $20^{\circ} \mathrm{S}$ to $20^{\circ} \mathrm{N}$, fourth column: $40^{\circ} \mathrm{N}$ to $55^{\circ} \mathrm{N}$, fifth column: $70^{\circ} \mathrm{N}$ to $90^{\circ} \mathrm{N}$ ) and two seasons (upper row: MAM, lower row: SON). The lower stratosphere part of the profile $(100 \mathrm{hPa}$ to $50 \mathrm{hPa}$, grey dashed box $)$ is expanded in the small inset in each graph.

latitudes. At lower pressures however, these differences vanish almost completely.

\subsection{Vertically resolved ozone}

Figure 2 shows mean climatological ozone profiles for the three data sets for the Antarctic $\left(90^{\circ} \mathrm{S}\right.$ to $\left.70^{\circ} \mathrm{S}\right)$, the tropics $\left(20^{\circ} \mathrm{S}\right.$ to $\left.20^{\circ} \mathrm{N}\right)$, the Arctic $\left(70^{\circ} \mathrm{N}\right.$ to $\left.90^{\circ} \mathrm{N}\right)$, the $\mathrm{SH}$ midlatitudes $\left(55^{\circ} \mathrm{S}\right.$ to $\left.40^{\circ} \mathrm{S}\right)$, and the $\mathrm{NH}$ mid-latitudes $\left(40^{\circ} \mathrm{N}\right.$ to $55^{\circ} \mathrm{N}$ ), for two different seasons (MAM and SON). Climatological values are lowest for the BDBP data set in the lower stratosphere for the mid- and high latitudes. In particular, there are distinctly lower ozone values over Antarctica in spring, which exist throughout the stratosphere. This might be mainly based on the fact that a logarithmic transformation of the input data allows the BDBP regression model to track low ozone values well (Bodeker et al., 2013). By $50 \mathrm{hPa}$ the differences between the BDBP climatology and the two other data sets become smaller. At the $30 \mathrm{hPa}$ level, all three data sets climatologies are almost identical in the tropics, and BDBP is only slightly lower in the high latitudes. Between approximately 30 and $7 \mathrm{hPa}$ the differences between data sets change sign in the tropics, with BDBP having higher climatological ozone values. However, in the polar regions, RW07 is consistently higher than BDBP, and often higher than SPARC between 30 and $7 \mathrm{hPa}$. In the tropics RW07 shows the highest climatological values again above about $7 \mathrm{hPa}$, placing the maximum climatological ozone value clearly higher in altitude than BDBP and SPARC. Climatologies for the SH mid-latitudes show the three data sets in good agreement up to about $20 \mathrm{hPa}$, at which point the differences between them get more apparent with BDBP showing the lowest values, and RW07 showing the highest. In the NH mid-latitudes the climatologies of SPARC and BDBP are almost identical for the whole profile, whereas RW07 is slightly higher in the lower stratosphere and from about $7 \mathrm{hPa}$ upward.

These differences in climatologies throughout the stratosphere could be caused by the different measurements used as input data for the regression models (e.g. the low ozone in Antarctic spring in BDBP). In addition, the different covered time periods on which the BDBP climatology and the FK98 climatology (basis for the RW07 and SPARC climatologies) are based could cause some differences in climatological values. Furthermore, the fact that the RW07 data set had to be converted into mixing ratio units and interpolated onto pressure levels (see Sect. 2.1) might influence the pressure assignment. Conversion sensitivity studies (see the Supplement) showed that the peak height of the maximum ozone is only slightly influenced by the conversion from altitude onto pressure levels. However, the associated absolute values of the RW07 ozone profiles can differ significantly depending on latitude and season, with largest differences in polar regions. The conversion chosen for the comparison shown in this study is not the exact replica of the conversion used to create the RW07 data set (combination of $7 \mathrm{~km}$ scale height and zonal mean, monthly mean temperature climatology (W. Randel, personal communication, 2012)); however, it puts the RW07 data on average closest to SPARC and BDBP.

\section{Anomalies}

Figure 3 shows the ozone column anomalies for each of the data sets, relative to their respective 1979 to 2005 climatologies, together with observational data from TOMS/SBUV (Stolarski and Frith, 2006). This provides an overview of the 


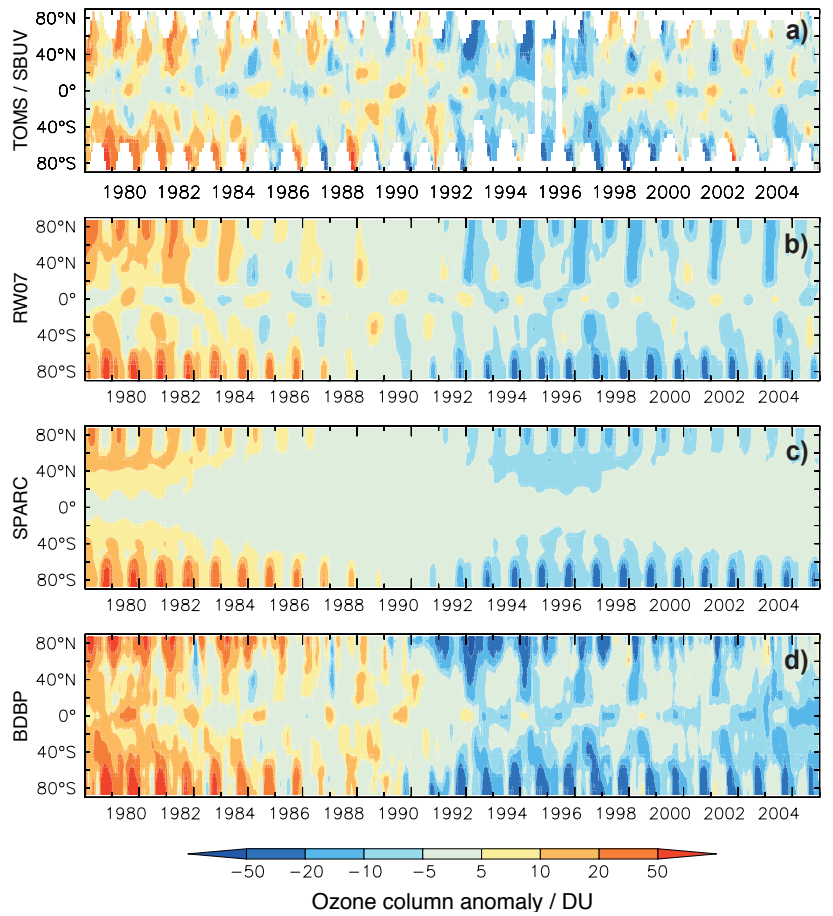

Fig. 3. Total column ozone anomalies (with respect to 1979 to 2005) as a function of time and latitude, for (a) TOMS/SBUV and integrated ozone from lowest to highest level available, for the three data sets, (b) RW07, (c) SPARC, and (d) BDBP. White regions in (a) indicate where no TOMS/SBUV data were available. Blue colours indicate negative anomalies, red colours indicate positive anomalies.

general ozone evolution and the degree of variability captured by the three data sets. Column data for TOMS/SBUV, SPARC and BDBP all include tropospheric ozone, while this is excluded with RW07, which begins at a climatological tropopause. However, by comparing the anomalies, we remove this systematic bias (assuming that the changes in the tropospheric burden make small contributions) and focus on interannual variability. The approach is supported by the fact that the anomalies calculated from the layered SBUV/2 data set (Bhartia et al., 2004), where ozone was integrated from approximately $64 \mathrm{hPa}$ upward, show a very similar pattern to those of the TOMS/SBUV (albeit with slightly weaker positive anomalies at the beginning of the time series and slightly stronger negative anomalies at the end of the time series), suggesting that tropospheric ozone only has a small influence on the total column ozone anomalies.

The TOMS/SBUV anomalies (Fig. 3a) show the wellknown pattern of the ozone hole evolution in the SH polar region, with positive anomalies before the late 1980s and increasingly more negative anomalies thereafter. The TOMS/SBUV data are only available when the satellite can see the sun, meaning that anomalies cannot be calculated at high latitudes for all months. Figure $3 \mathrm{a}$ also shows that ozone depletion is apparent in the $\mathrm{NH}$ polar region, although not as strong as in the SH. In the early 1990s, ozone anomalies were especially low when unusually deep $\mathrm{NH}$ polar ozone depletion was recorded (see, e.g., Newman et al., 1997). Interannual variability is considerable in the tropics and sub-tropics, where, in particular, the QBO signal is strong.

Figure $3 b$ to $d$ show that all three data sets show the development of SH ozone depletion in spring and the Antarctic ozone hole. The most negative anomalies at high southern latitudes appear in the mid-1990s, with similar magnitudes in all data sets. In addition, all data sets show negative $\mathrm{NH}$ anomalies in the boreal spring, but the deepest $\mathrm{NH}$ ozone depletion appears in the BDBP data. The presence of these more negative anomalies in the BDBP data is likely due, in part, to the volcanic basis functions: several studies have linked enhanced ozone depletion to the eruption of Mt. Pinatubo (e.g. Rosenfield et al., 1997; Solomon et al., 1998; Telford et al., 2009). In addition, Bodeker et al. (2013) ascribe the distinct negative Arctic ozone anomalies during the late 1990s and early 2000s in the BDBP data set to an underestimation of the dynamically forced ozone increases, which is not tracked by the regression model due to the lack of an appropriate basis function. The BDBP more closely replicates the TOMS/SBUV NH polar temporal evolution, but its anomalies are more positive in the beginning of the time period (early 1980s), and stay more negative at the end of the time period. Overall, this results in a larger negative trend in BDBP than in SPARC, RW07 or TOMS/SBUV.

Outside of the polar regions, the impact of the inclusion of additional basis functions in the BDBP regression model is clearly apparent, with the anomalies having much more structure than in RW07 and, especially, in the SPARC data. The BDBP variability compares well to the TOMS/SBUV anomalies, suggesting that the BDBP data set is in this sense closer to reality than RW07 or SPARC. The lack of a QBO basis function in the SPARC data leads to the anomalies in the tropical and mid-latitudes having very little temporal structure. Tropical ozone decreases are strongest in the BDBP data. The evolution of the tropical column ozone anomalies is well captured by the RW07. However, as for the $\mathrm{NH}$ polar region, tropical ozone depletion in the BDBP data set might be too strong, whereas it might be slightly too weak for SPARC. The exclusion of a (possibly changing) tropospheric column contribution could contribute to these differences.

Analysis of data set anomalies on different pressure levels (not shown) reveals characteristics similar to those evident in the integrated ozone anomalies. Antarctic ozone depletion is present in RW07 up to about $50 \mathrm{hPa}$, weakening at higher altitudes. In the tropics and subtropics the RW07 anomalies are mainly characterised by a QBO pattern. As with the integrated anomalies, vertically resolved SPARC anomalies show the least variability of all three data sets. Polar ozone depletion and a general global tropical decreasing trend are represented, the latter being comparable in magnitude to RW07 for all pressure levels. The relatively low 
variability for SPARC is to be expected given the smaller number of basis functions included in the fit.

As Fig. 3, the BDBP data set shows the more interannual variability than the other regression-based data sets, but it does agree reasonably well with the other data sets in the evolution of Antarctic anomalies. The Antarctic ozone depletion signal correlates across different pressure levels up to $10 \mathrm{hPa}$, although weakening with increasing altitude. In the Arctic, ozone depletion in the BDBP is stronger than the other two data sets. The most negative anomalies in this region appear at pressure levels up to $50 \mathrm{hPa}$ in $1992 / 1993$, following the Mt. Pinatubo eruption, but this strong anomaly disappears at higher altitudes. Negative tropical ozone anomalies are also largest for BDBP, peaking in the 2000s. In the lower stratosphere, the tropical BDBP anomalies do not show the QBO pattern as prominently as RW07, but the QBO-signal extends further into the mid-latitudes. The BDBP QBO pattern is more clearly apparent in the mid-stratosphere and with more variability than RW07.

\section{Time series}

Although the comparison of the vertically integrated ozone climatologies, and anomalies of the three different data sets against TOMS/SBUV provides some validation of the three data sets, high-latitude data gaps in the TOMS/SBUV data preclude validation for those regions. For this reason, we compare the three data sets against data from several vertically resolved measurement systems, particularly during time of polar darkness, providing additional validation. The following four sub-sections provide a more detailed description of the comparison of the ozone time series in the Arctic and the Antarctic, the NH mid-latitudes, and also in the tropics. An expanded range of these comparisons can be found in the Supplement.

We use vertical profiles from the satellite-mounted SAGE I and II, HALOE, POAM II and III instruments, and ozonesondes from Hassler et al. (2008). These data are stored on a common vertical grid and are quality checked, but are otherwise unaltered. In addition, we use SBUV/2 monthly mean layer data (Bhartia et al., 2004), and data from the Microwave Limb Sounder (MLS) on the Upper Atmosphere Research Satellite (UARS) (Livesey et al., 2003) and the Earth Observing System (EOS Aura) (Livesey et al., 2008) at pressure levels and latitude regions where they are available. This latter data set acts as a fully independent data source since it is not used in any of the three data sets as input for the regression models.

\subsection{Northern Hemisphere polar region}

Figure 4 shows the January and April time series of $80^{\circ}-$ $85^{\circ} \mathrm{N}$ lower stratospheric ozone at four pressure levels from the three different data sets with individual measurements

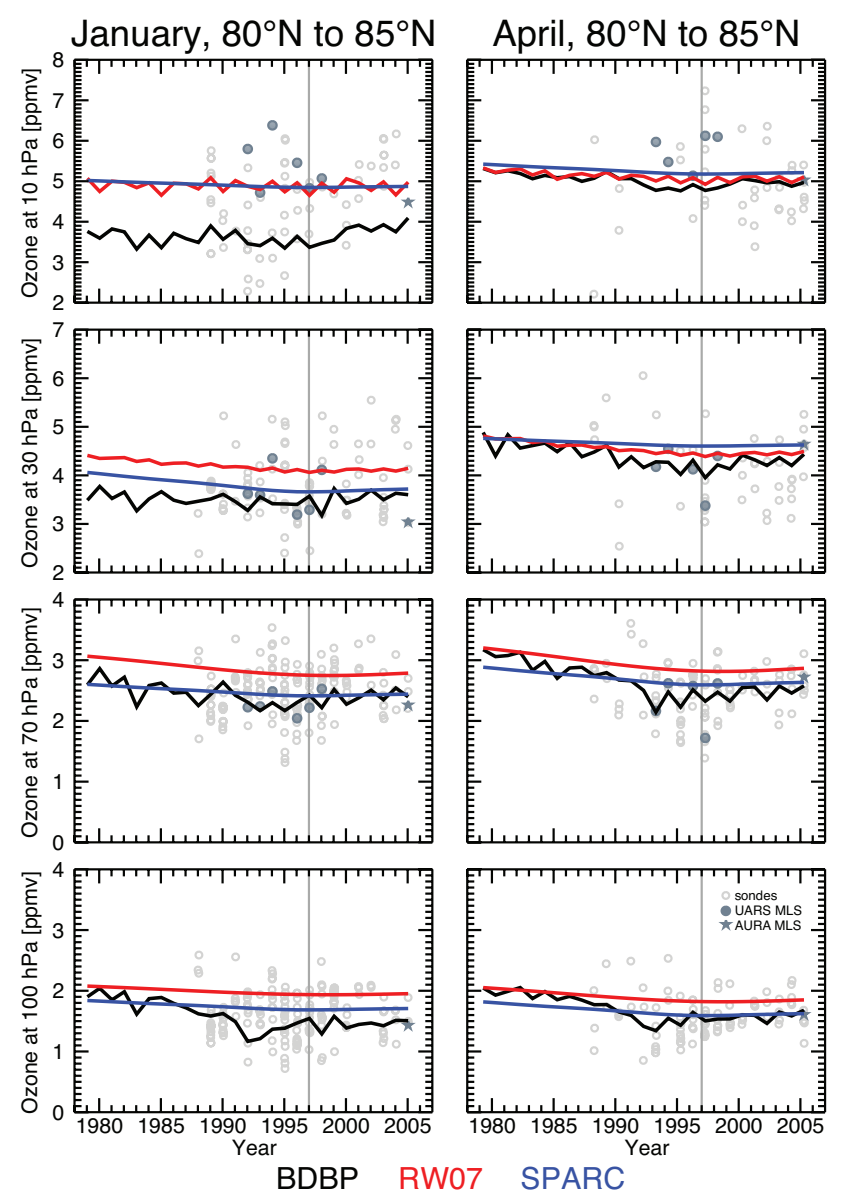

Fig. 4. January (left) and April (right) ozone time series $80^{\circ} \mathrm{N}$ to $85^{\circ} \mathrm{N}$ for four different pressure levels. Individual ozonesonde measurements available in this zone are shown for these months (grey open circles), together with UARS MLS monthly means (dark grey, filled circles) and AURA MLS monthly means (dark grey, filled stars), and the BDBP (black), RW07 (red) and SPARC (blue) time series. The vertical grey line denotes the inflection point selected for piecewise linear trend calculations (see Sect. 6).

from ozonesondes. Only ozonesonde data are shown between $80^{\circ} \mathrm{N}$ and $85^{\circ} \mathrm{N}$ as no satellite data are available for the comparison in that region. All ozonesonde measurements were taken at the two Canadian sounding stations, Eureka and Alert. There are more data at the levels lower in the atmosphere since the altitudes reached by the ozonesonde vary between soundings.

For both January and April, the RW07 and SPARC time series are almost identical in shape at 100 and $70 \mathrm{hPa}$, although SPARC is consistently lower. At 30 and $10 \mathrm{hPa}$ RW07 shows more variability than SPARC, due to the QBO basis functions used to create this data set, and, furthermore, the offset between RW07 and SPARC becomes smaller. The BDBP time series shows the most variability at all pressure levels, with distinct QBO related features and, especially in the lower stratosphere, influences of the Mt. Pinatubo 
- mboxeruption. In the lower stratosphere, the BDBP time series shows larger changes between the beginning of the time series and the mid-1990s. The overall slope of the BDBP time series is more similar to RW07 and SPARC at altitudes above $70 \mathrm{hPa}$, and the QBO-related variability dominates the time series structure. The BDBP time series shows lower ozone levels than RW07 at all pressure levels. Compared to SPARC, BDBP ozone is lower at 30 and $10 \mathrm{hPa}$, but more similar at 100 and $70 \mathrm{hPa}$. Offsets between BDBP and the other two data sets appear to depend on season, most likely due to the data set differences in climatologies (Sect. 3).

Time series of all three data sets fall within the range of the available ozonesonde measurements at all pressure levels despite their offsets, partly because the spread in the ozonesonde measurements is large. The RW07 time series tends to fall on the upper end of the ozonesonde data, whereas SPARC and BDBP fall within the middle of the ozonesonde range. In the absence of soundings earlier than the late 1980s, it is difficult to judge how well the ozone decrease in the $\mathrm{NH}$ polar region is represented in the three data sets. It is also unclear from this comparison which data set gives the most realistic ozone decrease as deduced from the raw measurements.

\subsection{Northern Hemisphere mid-latitudes}

Data availability is high for the Northern Hemisphere midlatitudes since this is a region frequently seen by satellites, and has a high density of sounding stations. Figure 5 shows the time series of ozone for the latitude band $45^{\circ} \mathrm{N}$ to $50^{\circ} \mathrm{N}$ for January and April, for the three ozone data sets and measurements from SAGE I and II, HALOE, ozonesondes, SBUV/SBUV2, UARS MLS and AURA MLS.

At all four pressure levels shown RW07 is slightly higher than BDBP in January, but similar to SPARC at $30 \mathrm{hPa}$ and $10 \mathrm{hPa}$. At these pressure levels, all three data sets are almost identical in April, with the most pronounced difference being the higher variability in RW07 and BDBP compared to SPARC. This is due to the higher number of basis functions used to create these data sets. In particular, a prominent QBO-like pattern in the RW07 and BDBP can be seen from $70 \mathrm{hPa}$ to $10 \mathrm{hPa}$. Overall, differences between the ozone data set time series are small, both in absolute values and in the estimated ozone decrease until the mid-1990s.

The spread in the individual measurements in winter and spring (e.g. January shown here) is high at all levels, and for all shown measurement systems, meaning that all three data set time series are well within the measurement range. Compared to January, the measurement frequency is less in April (with notably less measurements from SAGE II and HALOE), which likely contributes to the smaller variability in the measurements. Nevertheless, all three data sets are clearly within the range of the individual measurements.

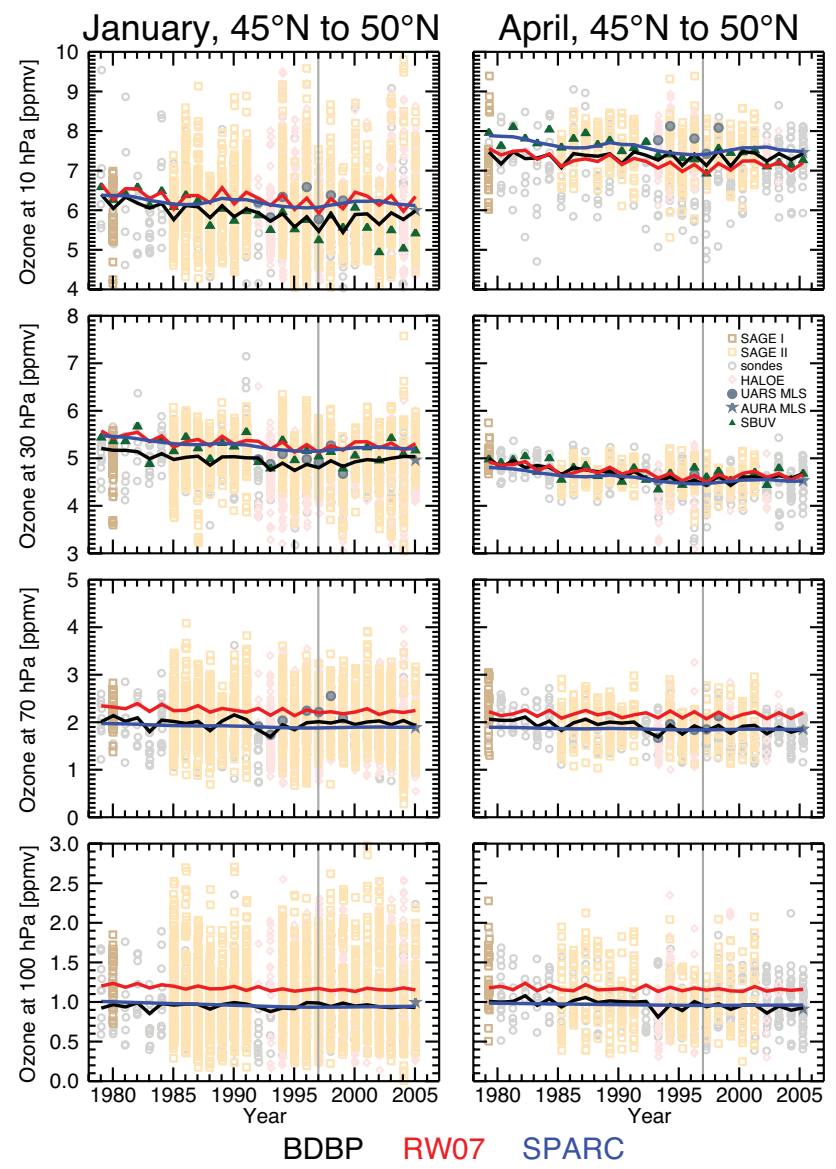

Fig. 5. January (left) and April (right) ozone time series $45^{\circ} \mathrm{N}$ to $50^{\circ} \mathrm{N}$ for four different pressure levels. Individual ozonesonde measurements available in this zone are shown for these months (grey open circles), together with SAGE I and II (orange open squares), HALOE (red open diamonds), and SBUV/SBUV2 (dark green, filled triangles), UARS MLS monthly means (dark grey, filled circles), AURA MLS monthly means (dark grey, filled stars), and the BDBP (black), RW07 (red) and SPARC (blue) time series are shown. The vertical grey line denotes the inflection point selected for piecewise linear trend calculations (see Sect. 6).

For more mid-latitude time series comparison (Northern and Southern Hemisphere) see the Supplement.

\subsection{Tropics}

Figure 6 shows the tropical ozone time series between $5^{\circ} \mathrm{S}$ and $5^{\circ} \mathrm{N}$ for all three data sets for April and July, together with ozonesonde measurements from seven stations (Brazaville/Congo, Malindi/Kenya, Nairobi/Kenya, San Cristobal/Ecuador, Christmas Island/Australia, Sepang/Malaysia, Kaashidoo/Maldives), and measurements from SAGE I and II, HALOE, and SBUV/SBUV2. Note that no data are available in April for RW07 at $100 \mathrm{hPa}$, as this is masked out by the climatological tropopause. 


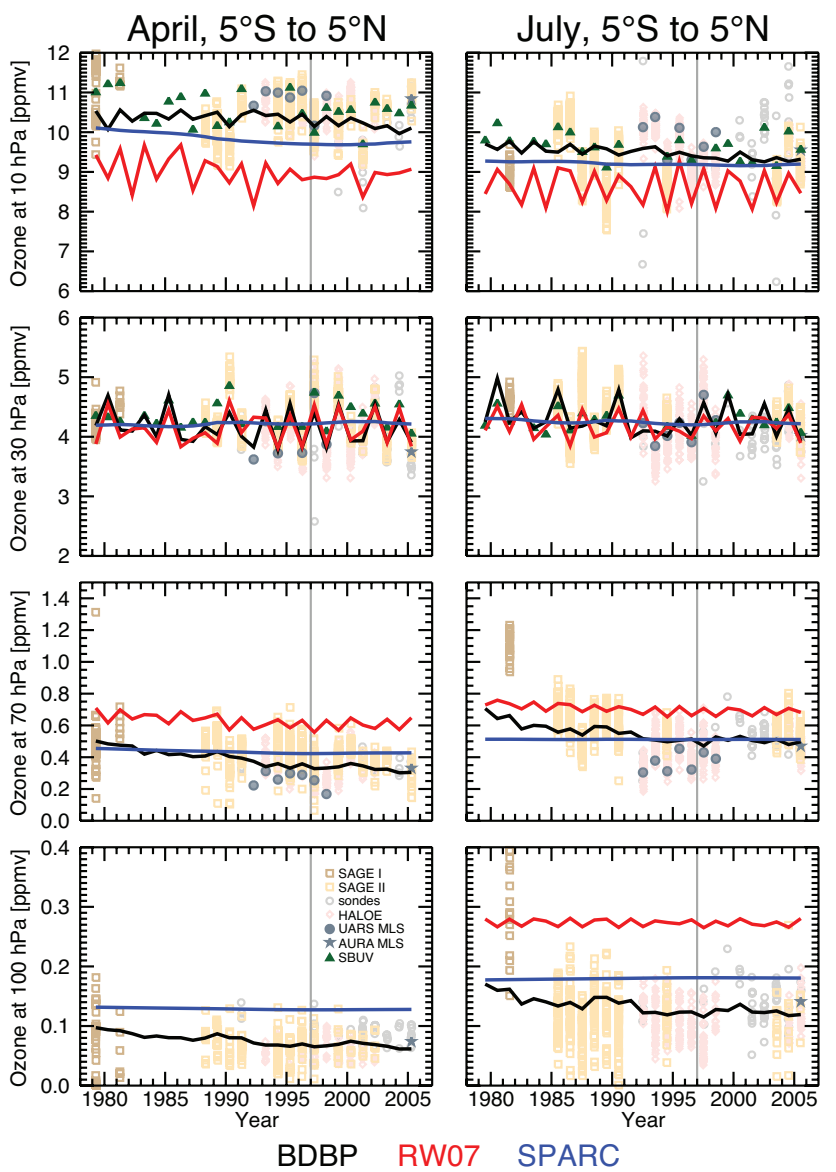

Fig. 6. April (left) and July (right) ozone time series between $5^{\circ} \mathrm{S}$ to $5^{\circ} \mathrm{N}$ for four different pressure levels. Individual ozonesonde (grey open circles), SAGE I and II (orange open squares), HALOE (red open diamonds), and SBUV/SBUV2 (dark green, filled triangles), UARS MLS monthly means (dark grey, filled circles), AURA MLS monthly means (dark grey, filled stars), and the BDBP (black), RW07 (red) and SPARC (blue) time series are shown. The vertical grey line denotes the inflection point selected for piecewise linear trend calculations.

For 100 and $70 \mathrm{hPa}$, values from the SPARC time series are bracketed by higher RW07 and lower BDBP values at the pressure levels shown. At $100 \mathrm{hPa}$ in July, RW07 is around $60 \%$ higher than SPARC, and $60 \%$ to $100 \%$ higher than BDBP. At $70 \mathrm{hPa}$, RW07 is only slightly higher than both BDBP and SPARC, but at $30 \mathrm{hPa}$ the three data sets are almost identical. The lack of a QBO basis function reduces the interannual variability in the SPARC time series, whereas both RW07 and BDBP show a strong QBO related pattern at $30 \mathrm{hPa}$, which is even more pronounced in RW07 at $10 \mathrm{hPa}$. In contrast to the $100 \mathrm{hPa}$ and $70 \mathrm{hPa}$, the RW07 time series is lower than the other two data sets at $10 \mathrm{hPa}$. For April at $10 \mathrm{hPa}$, the difference between the RW07 and SPARC time series ranges from $0.5 \mathrm{ppmv}$ to $1 \mathrm{ppmv}$, and between the RW07 and BDBP is at least 1 ppmv for all years. While all three data sets show minimal ozone decreases with

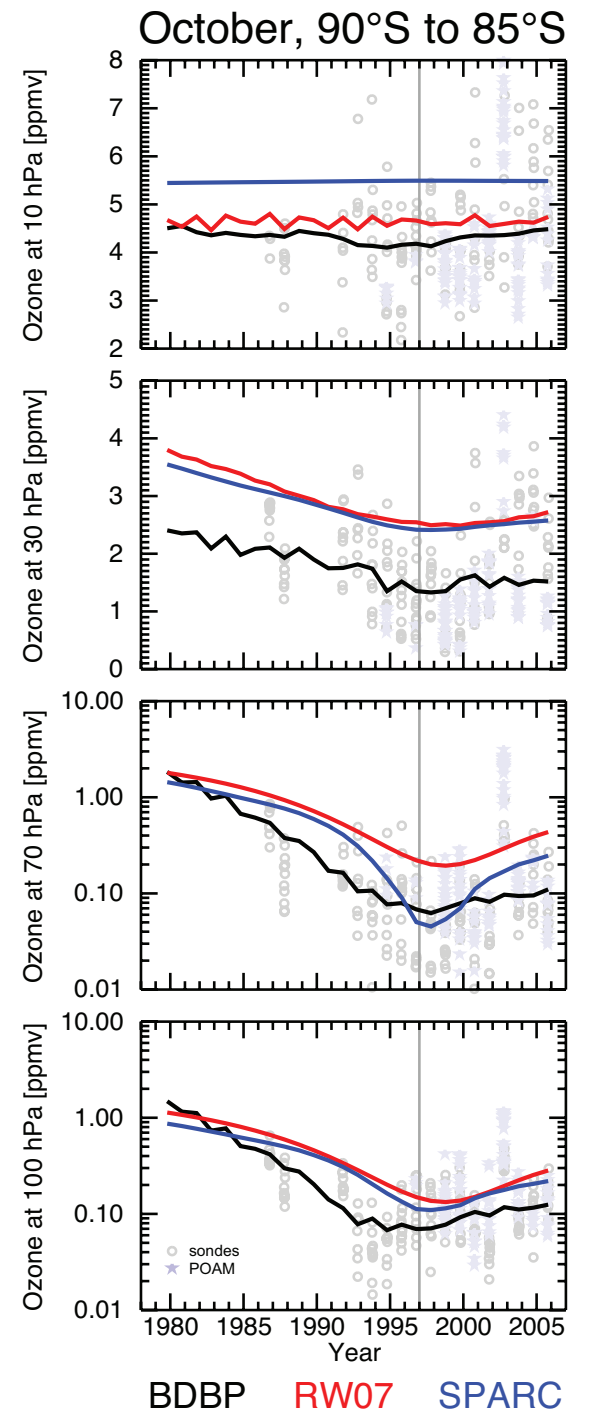

Fig. 7. October ozone time between $85^{\circ} \mathrm{S}$ and $90^{\circ} \mathrm{S}$ for four different pressure levels. Individual ozonesonde (grey open circles), and POAM II and III (violet starts), and the BDBP (black), RW07 (red) and SPARC (blue) time series are shown. The vertical grey line denotes the inflection point selected for piecewise linear trend calculations.

time at the $30 \mathrm{hPa}$ and $10 \mathrm{hPa}$ levels, at $70 \mathrm{hPa}$ and $100 \mathrm{hPa}$ a clear decrease in ozone is present in the BDBP time series from the beginning of the time series until the late 1990s (as described in Sect. 4).

Figure 6 also shows that the spread between measurements from the different data sources, and even between measurements from the same data source, can be large between $5^{\circ} \mathrm{S}$ and $5^{\circ} \mathrm{N}$. In particular, there is a step-function type difference between SAGE I (1979-1981) and later measurements. At $100 \mathrm{hPa}$ in July, RW07 ozone is substantially higher than all the measurements except SAGE I values, SPARC falls in the higher range of the measurements, whereas BDBP 
values are consistent with the data from the other sources. At the lowest pressure level $(10 \mathrm{hPa})$, the BDBP time series tracks the ozone values from the bulk of the measurements, whereas SPARC, and especially RW07, are at the lower range. While ozone decreases during the first 15 to $20 \mathrm{yr}$ of the period appear to be present in the measurements (e.g. July at $70 \mathrm{hPa}$ ), this decrease is linked to the ozone values provided by SAGE I at the very start of the period. Since the measurements are highly variable for the different months and over the analysed pressure range (see figures in the Supplement), the validity of this ozone depletion in the BDBP time series cannot be confirmed. On the other hand, the lack of ozone depletion in RW07 and SPARC also cannot be confirmed (Solomon et al., 2012).

\subsection{Southern Hemisphere polar region}

Figure 7 shows October ozone mixing ratios for the three data sets at $100,70,30$ and $10 \mathrm{hPa}$ for the latitude zone $85^{\circ} \mathrm{S}-90^{\circ} \mathrm{S}$, together with ozonesonde data from the South Pole station (the only station in this latitude band) and measurements from both POAM instruments, which are available from the mid-1990s onward. This time and location was chosen for comparison to examine the maximum depletion in the Antarctic ozone hole (e.g. Solomon, 1999). Note that the graphs for $100 \mathrm{hPa}$ and $70 \mathrm{hPa}$ are displayed with a logarithmic $y$-axis to show the severe depletions that are often measured within the ozone hole.

RW07 and SPARC time series for $100 \mathrm{hPa}$ and $30 \mathrm{hPa}$ are similar, with a strong ozone decrease through the late 1990s. At $10 \mathrm{hPa}$ SPARC is offset from RW07 and BDBP by about 1 ppmv. There is a QBO-like pattern in RW07, and there is no trend in SPARC, differing significantly from the other layers shown. The SPARC time series for $70 \mathrm{hPa}$ is somewhat unusual since it follows RW07 closely until the early 1990s and then drops to much lower values in the late 1990s. This is the atmospheric region of highest ozone depletion in Antarctic spring (e.g. Solomon et al., 2005) and a realistic representation of the degree of ozone depletion is important for climate change attribution studies with climate models, a task for which all three data sets are intended. BDBP shows a distinctly stronger and earlier ozone decrease than RW07 and SPARC at $100 \mathrm{hPa}$ and $70 \mathrm{hPa}$, but a similar trend at $30 \mathrm{hPa}$ and $10 \mathrm{hPa}$. BDBP is offset from the two other data sets by up to approximately $1.5 \mathrm{ppmv}$ at 30 and $10 \mathrm{hPa}$, but all three data sets start at approximately the same 1979 values at $100 \mathrm{hPa}$ and $70 \mathrm{hPa}$. BDBP appears to agree better with the South Pole observations, which is not surprising since this is the only data set to incorporate those data; both RW07 and SPARC only use observations from Syowa station at $69^{\circ} \mathrm{S}$. As ozone abundances reach lower values in the heart of the south polar vortex, this also explains why the ozone depletion is strongest with BDBP.

South Pole ozonesonde measurements show a clear decrease in ozone after the mid-1980s, with lowest values in the late 1990 s/early 2000 s, between $100 \mathrm{hPa}$ and $30 \mathrm{hPa}$. Although no electrochemical sonde data are available at the South Pole prior to 1986, Solomon et al. (2005) showed that earlier measurements there from the Brewer system also support a strong decline in ozone in the 1980s. The BDBP time series capture the decrease at the three lower levels, and are centred in the measurement spread. While the RW07 and SPARC underestimate the ozone depletion described by the measurements, the sharp decrease in SPARC at $70 \mathrm{hPa}$ from the early to late 1990s shifts that time series closer to the centre of the measurement spread. At $10 \mathrm{hPa}$, the spread in the measurements is large, encompassing the time series of all three data sets. SPARC lies at the higher end of the measurements, RW07 is lower than SPARC but still at the higher end of the measurements, and BDBP closer to the centre.

\section{Trends}

All three data sets that are part of this comparison are generated using multiple linear regression methods. Any ozone trends in these data sets are effectively imposed by their EESC basis function fit to the underlying measurements. Therefore, the purpose of the trends calculated in this section is to evaluate the differences between the three data sets, and to serve as reality-check when compared to trends derived directly from measurement time series.

We applied a multiple linear regression model to all three data sets, which was similar to that used to construct the three data sets, but replacing the EESC basis function with two piecewise linear trends (Reinsel et al., 2002). The inflection point, i.e. the time when the second trend term of the piecewise linear trend method is allowed to deviate from the first trend term, was set at the end of 1996, as suggested by Reinsel et al. (2002). This approach has also been applied to describe ozone depletion up to the peak of anthropogenic chlorine and bromine concentrations in the stratosphere (e.g. Newchurch et al., 2003; Steinbrecht et al., 2006; Jones et al., 2009). In addition to the two trend terms, the regression model included an offset term (to describe the average annual ozone amount) and basis functions to describe ozone variability due to the QBO, solar cycle and ENSO. Autocorrelation in the residuals of the regression model was considered (Bodeker et al., 1998). We focus our discussion on the results for the first trend term, describing the ozone change from the beginning of 1979 to the end of 1996, in the following sections.

\subsection{Annual mean trends}

Figure 8 shows the annual mean trends calculated from all three data sets for the period 1979 through 1996 as a function of latitude and pressure. This comparison focuses on the stratosphere, as the tropospheric trends are not statistically significantly different from zero for the analysed time period. 
Annual mean ozone trends displayed as a function of latitude and pressure or altitude show a distinct pattern: strong ozone depletion in the high-latitude lower stratosphere, with stronger trends in the SH than the NH (as suggested by total column ozone trends, e.g. WMO, 1999, Fig. 4-18; Randel and $\mathrm{Wu}, 2007)$, a weaker ozone decrease in the tropics, and a region in the middle stratosphere where trends are not statistically significantly different from zero (e.g. WMO, 1999, Fig. 4-32; Randel and Wu, 2007; McLinden et al., 2009). In the upper stratosphere between $40 \mathrm{~km}$ and $50 \mathrm{~km}(4 \mathrm{hPa}$ to $1 \mathrm{hPa}$ ) a stronger ozone decrease occurs again, especially in the high latitudes of both hemispheres (e.g. McLinden et al., 2009). These general features are all reproduced by all three data sets, although some differences exist. The polar lower stratosphere trends in RW07 and SPARC are very similar in structure and amplitude, and both show lower trends in the Arctic compared to the Antarctic. The maximum amplitude of the ozone depletion in Antarctica is slightly greater in RW07 than in SPARC. The BDBP shows larger ozone decreases at the highest latitudes near $100 \mathrm{hPa}$ to $70 \mathrm{hPa}$ in both polar regions, while the changes for RW07 and SPARC are constant in latitude poleward of the Syowa $\left(69^{\circ} \mathrm{S}\right)$ and Resolute $\left(75^{\circ} \mathrm{N}\right)$ ozonesonde stations, the two stations used as raw input for the polar regions in the RW07 and SPARC regression models.

Table 2 summarizes the mean decadal trends for different regions of the stratosphere for all three data sets. Differences in annual mean trends between RW07 and SPARC in the Antarctic lower stratosphere are about 2-3\% per decade. Trends for BDBP in this region are only slightly larger than RW07 (approx. 2\% more ozone decrease per decade); however, strong negative trends in BDBP extend into the middle stratosphere and farther into the mid-latitudes. Trends in the Arctic lower stratosphere from BDBP are much stronger than either RW07 or SPARC. Such a trend magnitude is not supported by total column ozone trend analyses (e.g. WMO, 1999, Fig. 4-18; Randel and Wu, 2007) and most likely is an artefact of the methods used in creating of the BDBP data set. Individual raw measurements in the Arctic (see Fig. 4) show a wide spread amongst measurements during the same month; however, a decrease in ozone over the years appears to exist in that latitude zone at least for the lower stratospheric pressure levels. The magnitude of this decrease in the BDBP data set is mainly determined by two factors: (1) the lack of measurements available at the beginning of the time series in this latitude zone, and (2) the presence of unusually low ozone values at the end of the fitting period (mid-1990s; WMO, 2003, Figs. 3-30 and 3-31); e.g. see the time series for $70 \mathrm{hPa}$ in April in Fig. 6. With no data to anchor the trend at the beginning of the time series, the method used to create the BDBP data set (Bodeker et al., 2013) likely overestimates the ozone decrease in the Arctic lower stratosphere.

The annual mean trends in the tropical lower stratosphere also differ considerably amongst the three data sets. Trends derived from RW07 and SPARC are similar, although they
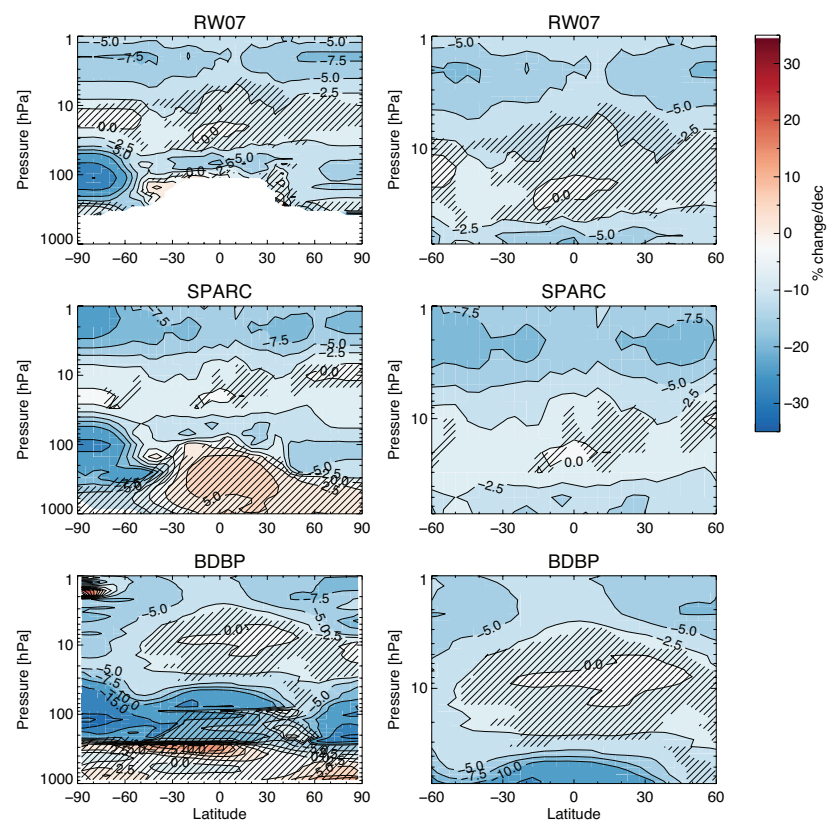

Fig. 8. Left column: Annual mean trend ( $\%$ per decade) as a function of latitude and pressure for the time period 1979 to 1996, for the RW07 data set, for the SPARC data set, and the BDBP data set. Hatched regions show trends that are not significantly different from zero at the $2 \sigma$ level. Blue colours indicate negative trends, red colours indicate positive trends. Contour levels are $\pm 35, \pm 30, \pm 25$, $\pm 20, \pm 15, \pm 10, \pm 7.5, \pm 5, \pm 2.5,0$. Right column: same as left column, but enlarged to the region $60^{\circ} \mathrm{S}$ to $60^{\circ} \mathrm{N}, 70 \mathrm{hPa}$ to $1 \mathrm{hPa}$. Note that no trend values are available for RW07 in the troposphere since RW07 is only defined in the stratosphere.

are slightly larger for RW07 (Fig. 8 left column and Table 2). BDBP trends are two to four times larger in that region. Forster et al. (2007) calculated tropical lower stratospheric ozone trends from SAGE II measurements between 1984 and 2005. While the trend pattern they obtained appears similar to the pattern shown for the BDBP trends (Forster et al., 2007), the magnitude of their trends is approximately $-5 \%$ to $-7 \%$ per decade. This is more similar to the range of the trends from RW07, but somewhat larger than the SPARC trends. Furthermore, Randel and Thompson (2011) combined SAGE II ozone measurements from $20^{\circ} \mathrm{S}$ to $20^{\circ} \mathrm{N}$ with tropical ozonesonde measurements for the period from 1984 and 2009 and estimated an ozone decrease of approximately $-4 \%$ per decade between 1984 and 2009 at $\sim 70 \mathrm{hPa}$. This too is closer to trends derived from RW07 and SPARC than to BDBP.

The comparisons suggest that it may be the inclusion of SAGE I data in the BDBP data set that is creating the anomalously large ozone trends in BDBP. However, trends shown in Fig. 8 and Table 2 describe the ozone changes from 1979 to 1996 , covering a different time period than either Forster et al. (2007) or Randel and Thompson (2011). Trends from these studies are therefore not 
Table 2. Annual and seasonal mean ozone trends and their $1 \sigma$ uncertainty for the three different data sets for four different atmospheric regions. Trends are given $\%$ per decade and are calculated for the time period 1979 to 1996 . Antarctic region: $90^{\circ} \mathrm{S}$ to $70^{\circ} \mathrm{S}$; Arctic region: $70^{\circ} \mathrm{N}$ to $90^{\circ} \mathrm{N}$; tropics: $20^{\circ} \mathrm{S}$ to $20^{\circ} \mathrm{N}$. DJF: December-January-February; MAM: March-April-May; JJA: June-July-August; SON: September-October-November.

\begin{tabular}{|c|c|c|c|}
\hline & RW07 & SPARC & BDBP \\
\hline \multicolumn{4}{|c|}{ Annual means } \\
\hline Antarctic lower strat. $[200-50 \mathrm{hPa}]$ & $-15.41 \pm 0.10$ & $-12.88 \pm 0.13$ & $-17.88 \pm 0.30$ \\
\hline Arctic lower strat. [200-50 hPa] & $-5.04 \pm 0.07$ & $-4.20 \pm 0.08$ & $-12.85 \pm 0.31$ \\
\hline Tropics, lower strat. [100-50 hPa] & $-4.70 \pm 0.21$ & $-2.58 \pm 0.21$ & $-12.74 \pm 0.53$ \\
\hline Upper strat. [10-1 hPa] & $-4.89 \pm 0.06$ & $-5.52 \pm 0.06$ & $-3.94 \pm 0.04$ \\
\hline \multicolumn{4}{|c|}{ Seasonal means - DJF } \\
\hline Antarctic lower strat. [200-50 hPa] & $-11.50 \pm 0.36$ & $-8.28 \pm 0.38$ & $-15.99 \pm 0.97$ \\
\hline Arctic lower strat. [200-50 hPa] & $-3.89 \pm 0.19$ & $-4.75 \pm 0.26$ & $-17.55 \pm 0.93$ \\
\hline Tropics, lower strat. [100-50 hPa] & $-5.49 \pm 0.77$ & $-3.43 \pm 1.03$ & $-13.38 \pm 2.11$ \\
\hline Upper strat. [10-1 hPa] & $-5.06 \pm 0.20$ & $-5.44 \pm 0.20$ & $-4.31 \pm 0.14$ \\
\hline \multicolumn{4}{|c|}{ Seasonal means - MAM } \\
\hline Antarctic lower strat. [200-50 hPa] & $-6.23 \pm 0.36$ & $-5.55 \pm 0.46$ & $-1.47 \pm 0.97$ \\
\hline Arctic lower strat. [200-50 hPa] & $-7.80 \pm 0.17$ & $-5.44 \pm 0.18$ & $-12.85 \pm 0.72$ \\
\hline Tropics, lower strat. [100-50 hPa] & $-3.93 \pm 0.26$ & $-2.48 \pm 0.64$ & $-12.68 \pm 2.10$ \\
\hline Upper strat. [10-1 hPa] & $-5.40 \pm 0.27$ & $-6.15 \pm 0.19$ & $-4.57 \pm 0.14$ \\
\hline \multicolumn{4}{|c|}{ Seasonal means - JJA } \\
\hline Antarctic lower strat. [200-50 hPa] & $-18.09 \pm 0.33$ & $-19.16 \pm 0.46$ & $-19.79 \pm 1.21$ \\
\hline Arctic lower strat. $[200-50 \mathrm{hPa}]$ & $-4.99 \pm 0.26$ & $-3.00 \pm 0.27$ & $-6.20 \pm 1.20$ \\
\hline Tropics, lower strat. [100-50 hPa] & $-4.09 \pm 0.66$ & $-1.53 \pm 0.49$ & $-11.74 \pm 1.41$ \\
\hline Upper strat. $[10-1 \mathrm{hPa}]$ & $-4.41 \pm 0.19$ & $-5.31 \pm 0.19$ & $-3.20 \pm 0.16$ \\
\hline \multicolumn{4}{|c|}{ Seasonal means - SON } \\
\hline Antarctic lower strat. [200-50 hPa] & $-28.11 \pm 0.38$ & $-19.33 \pm 0.40$ & $-38.17 \pm 0.89$ \\
\hline Arctic lower strat. [200-50 hPa] & $-2.46 \pm 0.27$ & $-3.05 \pm 0.36$ & $-15.24 \pm 1.36$ \\
\hline Tropics, lower strat. [100-50 hPa] & $-5.68 \pm 0.68$ & $-2.70 \pm 0.63$ & $-13.47 \pm 1.51$ \\
\hline Upper strat. [10-1 hPa] & $-4.58 \pm 0.19$ & $-4.83 \pm 0.19$ & $-3.10 \pm 0.14$ \\
\hline
\end{tabular}

necessarily directly comparable to the trends derived here. When the Forster et al. (2007) methodology is applied to the three data sets and linear trends calculated for the same time period (1984 to 2005), the trends derived from BDBP range from around $-7 \%$ to $-8 \%$ per decade in the tropical lower stratosphere, compared to around $-3 \%$ per decade for RW07 and around $-2 \%$ per decade for SPARC. BDBP trends then are similar to the trends reported by Forster et al. (2007), whereas RW07 and SPARC trends are clearly smaller.

Several studies show only annual mean trends between $60^{\circ} \mathrm{S}$ and $60^{\circ} \mathrm{N}$, from around $70 \mathrm{hPa}$ up to around $1 \mathrm{hPa}$ (e.g. Wang et al., 2002; McLinden et al., 2009; WMO, 2011, Fig. 2-4). This is the region of the stratosphere that is well covered by SAGE II measurements, and therefore trend calculations are rather straightforward there. Figure 8 (right column) shows the annual mean trends calculated from the three data sets, displayed for the same geographical and atmospheric region as the SAGE data. Trends at around $70 \mathrm{hPa}$ for RW07 are only slightly larger than for SPARC, and both agree well with trends derived from SAGE I/II by Wang et al. (2002). This is expected since both RW07 and SPARC are heavily based on SAGE data in this region. BDBP trends in this region can be more than double these values, especially in the tropics, which is likely due to additional data sources being used for the creation of the data set and the more complex regression method.

Another region of special interest for annual mean ozone trends is the upper stratosphere where a response to climate change (e.g. increasing greenhouse gas concentrations) is expected in addition to the impact of changes in ozone depleting substances. Upper stratospheric trends for all three data sets strengthen with increasing latitude, but are weaker than in the lower stratosphere (Fig. 8, left column). The magnitudes of the trends for the three data sets are similar, with BDBP showing a slightly weaker annual mean ozone decrease (ca. $-4 \%$ per decade) than RW07 (ca. -5\% decade) and SPARC (ca. $-5.5 \%$ per decade; Table 2). A small area of positive trends in the Antarctic in the BDBP data set, around 
$2 \mathrm{hPa}$, does not likely represent a real ozone increase from 1979 to 1997 , but is more likely caused by constraining errors of the BDBP regression method, as described by Bodeker et al. (2013). Overall, SPARC trends are slightly more negative than RW07 and BDBP in the tropics and mid-latitudes in the upper stratosphere. They are strongest in the SH polar region, poleward of $60^{\circ} \mathrm{S}$, and between $4 \mathrm{hPa}$ and $1 \mathrm{hPa}$ (see Cionni et al., 2011). This pattern does not appear in RW07 or BDBP.

SAGE data alone show trends in the upper stratospheric region up to $-8 \%$ per decade (McLinden et al., 2009) and slightly higher (Wang et al., 2002), with a very similar spatial pattern to the trend for the data sets. SPARC is the data set with trends closest to the SAGE trends. Trends derived by analysing only SBUV data, as shown in McLinden et al. (2009), are slightly lower (up to $-6 \%$ per decade) and are therefore closer to the trends derived from RW07 and BDBP.

\subsection{Seasonal trends}

Table 2 shows seasonal trends and their statistical uncertainties for the three different data sets. All calculated seasonal trends are statistically significant at the $2 \sigma$ level, except the MAM trend for BDBP in the SH polar lower stratosphere. Uncertainties are up to three times higher for the BDBP trends than for RW07 and SPARC, owing to the higher variability in this data set. The uncertainties presented in Table 2 show that the three data sets seldom overlap within their respective statistical errors, and it is structural uncertainties that dominate the differences between them. Nevertheless, it is useful to examine the seasonality of the statistical uncertainties.

Differences between the data sets are most pronounced for the tropical lower stratosphere, where BDBP trends are up to three times higher than RW07 and SPARC trends in all seasons (Solomon et al., 2012), although trends differ only slightly between the seasons for a given data set. Trends in the upper stratosphere also do not differ much for the different seasons, and the three different data sets are ranked in the same pattern for all seasons: BDBP shows the smallest trend, followed by RW07 and SPARC with the largest trends. In JJA BDBP trends are up to $40 \%$ smaller than those of SPARC; RW07 trends are up to $15 \%$ smaller than SPARC.

The largest seasonal difference in trends is present for the SH polar lower stratosphere. For BDBP, the trends are not significant in MAM and are approximately $-38 \%$ per decade in SON. Seasonal variability in trends for this region is not as high for RW07 and SPARC; however, both these data sets are similar with their smallest trends in MAM and their largest trends in SON. Trends for RW07 are larger than for SPARC (except JJA), and trends for BDBP are stronger than for RW07 (except MAM). Differences are largest in Antarctic spring (SON) when most ozone depletion happens: trends for BDBP are approximately $35 \%$ higher than RW07 trends, and twice as large as SPARC trends.
Trends in the NH polar lower stratosphere are largest in all seasons for BDBP, and are of comparable magnitude for RW07 and SPARC. Differences between BDBP and the other two data sets can reach up to four times the trend value (e.g. in DJF), and are only of comparable magnitude for JJA. Seasonal differences are largest for BDBP, ranging from $-18 \%$ per decade in DJF to $-6 \%$ per decade in JJA. The weakest seasonal cycle in trends is found for SPARC, where trends range from $-4.8 \%$ per decade in DJF to $3 \%$ per decade in JJA.

\section{$7 \quad$ Radiative forcing}

In this section, we compare the ozone radiative forcing implied by the three data sets. The ozone radiative forcing is defined as the net change in radiation entering the troposphere due to a change in ozone. The adjusted radiative forcing was computed, which is where stratospheric temperatures are adjusted to the ozone changes using the fixed dynamical heating approximation. This adjustment is a first order effect for stratospheric ozone changes, whereas for other forcing agents it is typically only a $10-20 \%$ effect.

The radiative forcing for stratospheric ozone changes is examined over the period of maximum ozone depletion, using averages of 1979-1981 for the background state and 1995-1997 for the heavily depleted period. Data from the International Satellite Cloud Climatology Project (ISCCP) are used for the temperature and cloud fields and the calculation is done using seasonal averages. This radiative forcing code is the same as used by Portmann et al. (2007), which has been shown to compare well with other codes (Forster et al., 2005).

Table 3 shows the computed radiative forcing values. Tropospheric ozone changes are not included because they are relatively small during this time period and because one of the data sets (RW07) does not include tropospheric ozone. The table shows the large cancellation between the instantaneous forcing and the stratospheric adjustment, which makes the accurate calculation of the total forcing sensitive to small differences. The uncertainty in the total radiative forcing is proportional to the instantaneous and adjustment values, meaning that even a modest $10 \%$ uncertainty in these values translates to a $0.03 \mathrm{Wm}^{-2}$ uncertainty in the total forcing. The BDBP data set induces considerably more radiative forcing than RW07 or SPARC data sets. This is a consequence of larger ozone decreases in the subtropics in both hemispheres and the SH mid-latitudes (see Fig. 9). The differences in radiative forcing between the ozone data sets imply different surface climate responses when the ozone data sets are used in climate models; further, the larger ozone decreases at mid- and high latitudes in the BDBP data set can be expected to cause larger responses of climatic modes of variability (e.g., the SAM and NAM) compared with RW07 and SPARC data sets. 
Table 3. The radiative forcing $\left(\mathrm{Wm}^{-2}\right)$ due to stratospheric ozone changes between 1979-1981 and 1995-1997. The instantaneous shortwave (SW), instantaneous longwave (LW), adjustment due to stratospheric temperature changes, and total radiative forcing are shown.

\begin{tabular}{lllll}
\hline & SW & LW & Adjustment & Total \\
\hline RW07 & 0.147 & -0.062 & -0.124 & -0.038 \\
SPARC & 0.141 & -0.061 & -0.113 & -0.033 \\
BDBP & 0.209 & -0.087 & -0.241 & -0.119 \\
\hline
\end{tabular}

\section{Discussion and summary}

This study describes three recent, long-term, global, zonal mean, ozone profile data sets. All three data sets are based on regression model output, and therefore the degree of variability described by them depends strongly on the number and the choice of basis functions used for their creation. Their climatologies, anomalies, and annual and seasonal trends have been compared with each other, as well as with several satellite-based and in situ measurements.

The overall pattern of the climatologies look very similar for all three data sets, and compare well to TOMS/SBUV data and the FK98 climatology. However, absolute values differ for the three data sets. RW07 tends to have the highest climatological values at lower and higher altitudes in the stratosphere, whereas it tends to be the lowest in the midstratosphere, implying that the vertical gradient in ozone is different to BDBP and SPARC. BDBP climatological values tend to be the lowest, possibly related to the fact that its underlying climatology is derived from the full 19792005 period of the input data. This is in contrast to RW07 and SPARC, which are both based on the FK98 climatology, covering 1980 to 1991 and based on low resolution SBUV data. The anomaly patterns from the three data sets differ markedly, with SPARC showing the least variability and BDBP showing the most, due to the different number of basis functions used. In general, BDBP shows the strongest ozone changes over the whole period (1979-2005), especially in the polar regions and the tropics, whereas SPARC shows the weakest. This is then reflected in the resulting radiative forcing estimates.

Comparisons with individual measurements from several different measurement systems show very good agreement of the overall magnitude of the ozone values with BDBP, good agreement with SPARC, and a slightly less good agreement with RW07. The biases present in the RW07 climatologies (see Sect. 3) also bias the overall magnitude of the time series. As a measure of how well the time series of the three data sets represent the ozone values measured by SAGE II, monthly mean, zonal mean values from all available, qualityscreened SAGE II measurements were calculated and interpolated onto the pressure levels from SPARC (see Sect. 2.2). The BDBP and RW07 data set were also interpolated onto

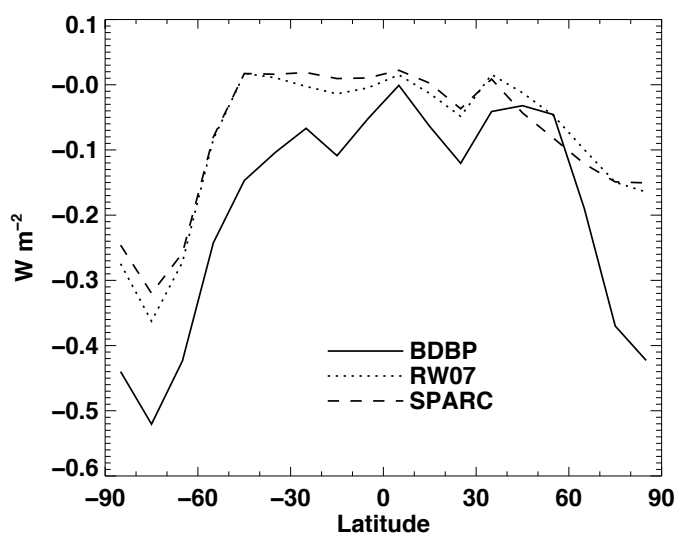

Fig. 9. Annual mean radiative forcing due to ozone changes between 1979-1981 and 1995-1997 averages for BDBP (solid line), RW07 (dotted line), and SPARC (dashed line) ozone data sets. The global mean values from these calculations are given in Table 3 (column total).

the same pressure levels. For each latitude zone and pressure level, the sum of the squared residuals between the available SAGE II data and the three data sets were calculated, then normalized to the number of the available SAGE II monthly means for that specific time series, and the resulting average squared difference related to the overall SAGE II mean of the whole time series for the respective latitude zone and pressure level. The results for this measure of matching the SAGE II data are shown in Fig. 10. Only pressure levels from $100 \mathrm{hPa}$ to $1 \mathrm{hPa}$ are shown since RW07 does not provide tropospheric data and SAGE II data is sparser lower down in the atmosphere. The match to SAGE II data is best for the BDBP data set with most of the average squared difference for the shown pressure levels being below $7.5 \%$, in the tropics and mid-latitudes even below $5 \%$. Average squared differences for SPARC are only slightly higher than for BDBP, but overall still mostly below $7.5 \%$. For RW07 the average squared differences are clearly higher than for the other two data sets, with the majority of the values below $40 \%$. As mentioned above, the bias that is present in the RW07 climatologies cause the bias for the overall time series, and increases therefore the difference of the RW07 time series from SAGE II.

A second set of monthly means was calculated from global ozonesonde data. The calculated average squared differences between the three data sets and the ozonesonde measurements are shown in Fig. 11. Only pressure levels from $100 \mathrm{hPa}$ to $10 \mathrm{hPa}$ are considered for this comparison since ozone soundings often do not reach altitudes above the $10 \mathrm{hPa}$ pressure level. For all three data sets the agreement with the ozonesondes is not as good as with SAGE II data, with more values in the range of $10 \%$ and $30 \%$ than before. This might be partially caused by spatially biased zonal means. Longitudinal biases are possible for the different latitude zones due to the location of the available 

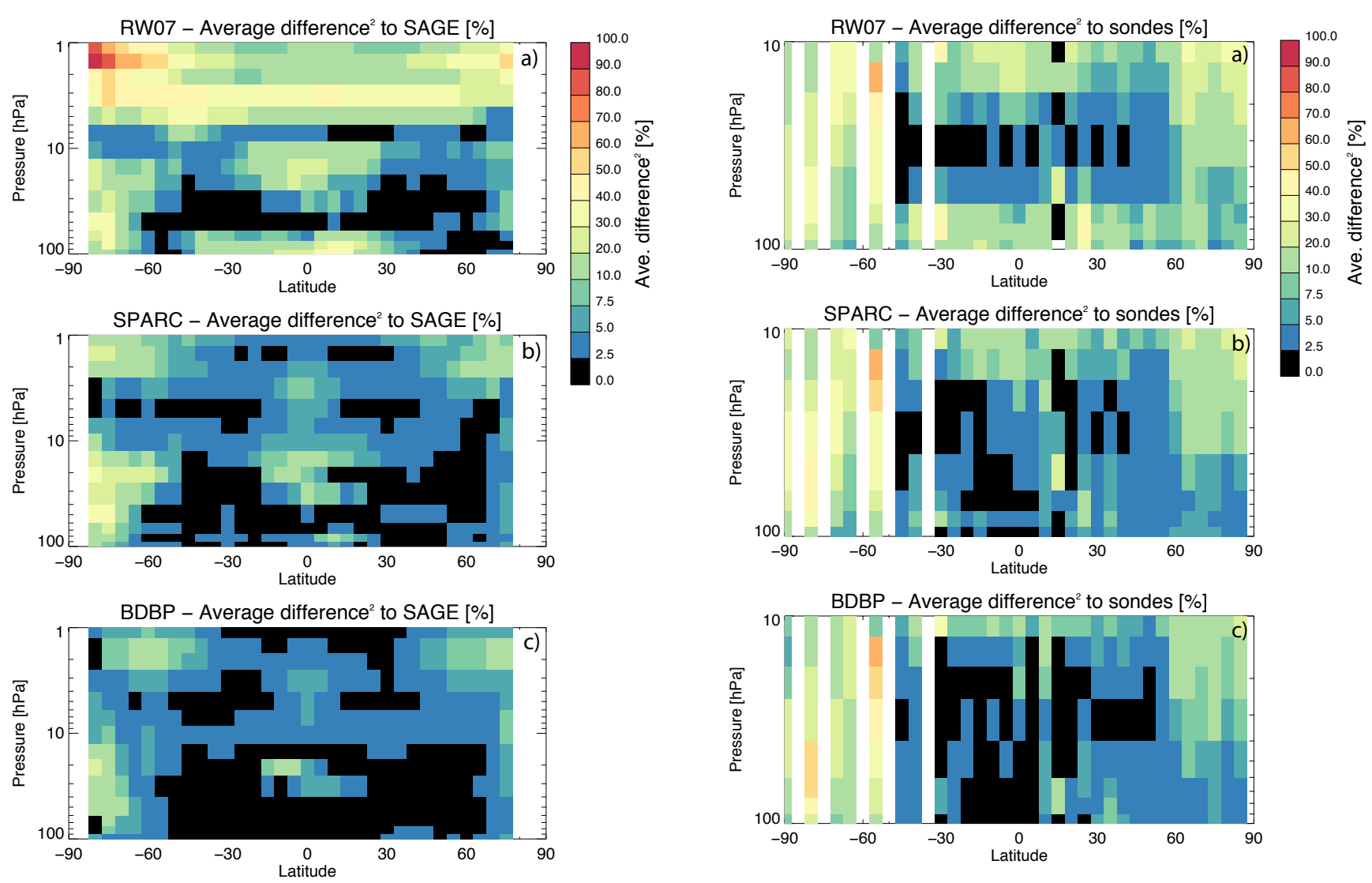

Fig. 10. Average squared difference between all available monthly mean SAGE II values for given latitude bands and pressure levels, and (a) the RW07 data set, (b) the SPARC data set, and (c) the BDBP data set, given in percent. Note that for RW07 at $100 \mathrm{hPa}$ some monthly means are not available between $20^{\circ} \mathrm{S}$ and $25^{\circ} \mathrm{N}$ due to missing tropospheric data. Colours changing from black to red indicate a change in average squared differences from $0 \%$ to $100 \%$.

ozone sounding stations. While these were considered for the creation of the monthly means for the BDBP regression (Bodeker et al., 2013), they were not considered for the calculation of the average squared differences shown in Fig. 11. Overall, the comparisons of the three data sets to sonde data are similar to the comparisons with SAGE II data: differences between BDBP and sondes are smallest, they are slightly larger for SPARC and sondes, and largest for RW07 and sondes. Average squared differences between SAGE II and the ozonesonde measurements are predominately below 7.5\% (see the Supplement), so differences between data sets and either SAGE II or sondes of that magnitude fall within the range of measurements uncertainties.

For global climate modellers, the best choice of ozone data set for their model studies will depend on the application. Although all three data sets cover the same time period and the whole globe, clear differences exist between them that would likely influence the model results. For example, Solomon et

Fig. 11. Average squared difference between all available monthly mean ozone sonde values for given latitude bands and pressure levels, and (a) the RW07 data set, (b) the SPARC data set, and (c) the BDBP data set, given in percent. Note that for RW07 at $100 \mathrm{hPa}$ some monthly means are not available between $20^{\circ} \mathrm{S}$ and $25^{\circ} \mathrm{N}$ due to missing tropospheric data. Colours changing from black to red indicate a change in average squared differences from $0 \%$ to $100 \%$.

al. (2012), showed that the modelled temperature response in the tropical lower stratosphere is significantly larger if the BDBP data set is used in a climate model, compared to simulations with SPARC or RW07. Given the difficulties in determining the uncertainties in both ozone trends and the resulting ozone forcing for each of the three data sets, the availability of all three, provides some indication of how accurately trends are known. This allows climate modellers to estimate the impact of this uncertainty, as well as the sensitivity of climate responses to different ozone forcings.

Strength and weaknesses of the three data sets can therefore be summarized as follows:

- RW07: This data set captures the main features of the observed variability. Due to its original format in DU $/ \mathrm{km}$ and on altitude levels, the conversion onto pressure levels and into mixing ratio is likely to introduce biases. Climatologies of this data set are biased high over much of the lower stratosphere and biased low over 
much of the upper stratosphere. Trends in the NH polar regions and the tropics might be slightly too weak, and are clearly too weak in the SH polar regions. The data from the two ozonesonde stations in the northern and southern polar regions that are used to describe the high-latitude ozone changes might not capture the full extent of the spring ozone depletion since they are both located at the edge of the respective polar vortex, and might therefore sample ozone-rich air from outside the vortex at times.

- SPARC: The variability provided in this data set is small compared to observations. The described trends are likely too small, and the underlying climatology that is based on the FK98 climatology might be biased high in some latitude and pressure regions.

- BDBP: In this data set the described variability is closest to the observations, as are the climatologies. Trends in the $\mathrm{SH}$ polar regions are well represented, although trends in the $\mathrm{NH}$ polar regions appear to be overestimated. Additionally, some artefacts of the applied regression method might be present in the $\mathrm{SH}$ upper stratosphere.

Based on the comparisons in this study, and the above summarized strengths and weaknesses of the three data sets, the following features of each data set can be deduced, which bears on their utility in different applications:

- RW07 - This data set shows a more conservative estimate of tropical and polar ozone changes than the BDBP data set, but does not match absolute ozone observations well in some latitudinal and atmospheric regions. This data set would be most useful where only ozone anomalies are necessary for a particular study, or when a more conservative ozone change estimate is desired.

- SPARC - This is the only data set that extends before and beyond when observations are available; it runs from 1850 to 2100 . This data set is indicated for studies that require historical or future ozone, are not concerned with much variability (besides the annual cycle), and where the users are aware of the likely conservative ozone changes for the 1979-2007 period.

- BDBP - This data set includes more detailed interannual variability and shows excellent agreement with the raw data from SAGE II and ozonesonde. It displays the largest ozone changes over much of the lower stratosphere, and in particular the SH polar regions. This data set is recommended for studies that focus on these characteristics.

\section{Supplementary material related to this article is available online at: http://www.atmos-chem-phys.net/13/ 5533/2013/acp-13-5533-2013-supplement.zip.}

Acknowledgements. Funding for B. Hassler has been provided by the NOAA NCDC Climate Data Records Program. The authors want to thank Bill Randel for helpful comments and discussion about the manuscript. We thank two anonymous reviewers and T. G. Shepherd for helpful comments and suggestions on how to improve the manuscript.

Edited by: W. Lahoz

\section{References}

Bhartia, P. K., McPeters, R. D., Stolarski, R. S., Flynn L. E., and Wellemeyer, C. G.: A quarter century of ozone observations by SBUV and TOMS, Proceedings of the XX Quadrennial Ozone Symposium, Kos, 1-8 June, Greece, 2004.

Bodeker, G. E., Boyd, I. S., and Matthews, W. A.: Trends and variability in vertical ozone and temperature profiles measured by ozonesondes at Lauder, New Zealand: 1986-1996, J. Geophys. Res., 103, 28661-28681, 1998.

Bodeker, G. E., Hassler, B., Young, P. J., and Portmann, R. W.: A vertically resolved, global, gap-free ozone database for assessing or constraining global climate model simulations, Earth Syst. Sci. Data, 5, 31-43, doi:10.5194/essd-5-31-2013, 2013.

Cionni, I., Eyring, V., Lamarque, J. F., Randel, W. J., Stevenson, D. S., Wu, F., Bodeker, G. E., Shepherd, T. G., Shindell, D. T., and Waugh, D. W.: Ozone database in support of CMIP5 simulations: results and corresponding radiative forcing, Atmos. Chem. Phys., 11, 11267-11292, doi:10.5194/acp-11-11267-2011, 2011.

Dall'Amico, M., Stott, P. A., Scaife, A. A., Gray, L. J., Rosenlof, K. H., and Karpechko, A. Y.: Impact of stratospheric variability on tropospheric climate change, Clim. Dynam., 34, 399-417, doi:10.1007/s00382-009-0580-1, 2009.

Dall'Amico, M., Gray, L. J., Rosenlof, K. H., Scaife, A. A., Shine, K. P., and Stott, P. A.: Stratospheric temperature trends: impact of ozone variability and the QBO, Clim. Dynam., 34, 381-398, doi:10.1007/s00382-009-0604-x, 2010.

Daniel, J. S., Solomon, S., and Albritton, D. L.: On the evaluation of halocarbon radiative forcing and global warming potentials, J. Geophys. Res., 100, 1271-1285, 1995.

Forster, P. M. d. F, Burkholder, J. B., Clerbaux, C., Coheur, P. F., Dutta, M., Gohar, L. K., Hurley, M. D., Myhre, G., Portmann, R. W., Shine, K. P., Wallington, T. J., and Wuebbles, D.: Resolution of the uncertainties in the radiative forcing of HFC-134a, J. Quant. Spectrosc. Radiat. Transfer, 93, 447-460, 2005.

Forster, P. M., Bodeker, G., Schofield, R., Solomon, S., and Thompson, D.: Effects of ozone cooling in the tropical lower stratosphere and upper troposphere, Geophys. Res. Lett., 34, L23813, doi:10.1029/2007GL031994, 2007.

Fortuin, J. P. F. and Kelder, H.: An ozone climatology based on ozonesonde and satellite measurements, J. Geophys. Res., 103, 31709-31734, 1998.

Gillett, N. P. and Thompson, D. W. J.: Simulation of recent Southern Hemisphere climate change, Science, 302, 273-275, doi:10.1126/science.1087440, 2003. 
Hassler, B., Bodeker, G. E., and Dameris, M.: Technical Note: A new global database of trace gases and aerosols from multiple sources of high vertical resolution measurements, Atmos. Chem. Phys., 8, 5403-5421, doi:10.5194/acp-8-5403-2008, 2008.

Jones, A., Urban, J., Murtagh, D. P., Eriksson, P., Brohede, S., Haley, C., Degenstein, D., Bourassa, A., von Savigny, C., Sonkaew, T., Rozanov, A., Bovensmann, H., and Burrows, J.: Evolution of stratospheric ozone and water vapour time series studied with satellite measurements, Atmos. Chem. Phys., 9, 6055-6075, doi:10.5194/acp-9-6055-2009, 2009.

Livesey, N. J., Read, W. G., Froidevaux, L., Waters, J. W., Santee, M. L., Pumphrey, H. C., Wu, D. L., Shippony, Z., and Jarnot, R. F.: The UARS microwave limb sounder version 5 data set: Theory, characterization, and validation, J. Geophys. Res., 108, 4378, doi:10.1029/2002JD002273, 2003.

Livesey, N. J., Filipiak, M. J., Froidevaux, L., Read, W. G., Lambert, A., Santee, M. L., Jiang, J. H., Pumphrey, H. C., Waters, J. W., Cofield, R. E., Cuddy, D. T., Daffer, W. H., Drouin, B. J., Fuller, R. A., Jarnot, R. F., Jiang, Y. B., Knosp, B. W., Li, Q. B., Perun, V. S., Schwartz, M. J., Snyder, W. V., Stek, P. C., Thurstans, R. P., Wagner, P. A., Avery, M., Browell, E. V., Cammas, J. P., Christensen, L. E., Diskin, G. S., Gao, R.-S., Jost, H. J., Loewenstein, M., Lopez, J. D., Nedelec, P., Osterman, G. B., Sachse, G. W., and Webster, C. R.: Validation of Aura Microwave Limb Sounder $\mathrm{O}_{3}$ and $\mathrm{CO}$ observations in the upper troposphere and lower stratosphere, J. Geophys. Res., 113, D15S02, doi:10.1029/2007JD008805, 2008.

McCormick, M. P., Zawodny, J. M., Viega, R. E., Larson, J. C., and Wang, P. H.: An overview of SAGE I and II ozone measurements, Planet. Space Sci., 37, 1567-1586, 1989.

McLinden, C. A., Tegtmeier, S., and Fioletov, V.: Technical Note: A SAGE-corrected SBUV zonal-mean ozone data set, Atmos. Chem. Phys., 9, 7963-7972, doi:10.5194/acp-9-7963-2009, 2009.

Miller, R. L., Schmidt, G. A., and Shindell, D. T.: Forced annular variations in the 20th century Intergovernmental Panel on Climate Change Fourth Assessment Report models, J. Geophys. Res., 111, D18101, doi:10.1029/2005JD006323, 2006.

Newchurch, M. J., Yang, E. S., Cunnold, D. M., Reinsel, G. C. Zawodny, J. M., and Russell, J. M.: Evidence for slowdown in stratospheric ozone loss: First stage of ozone recovery, J. Geophys. Res., 108, 4507, doi:10.1029/2003JD003471, 2003.

Newman, P. A., Gleason, J. F., McPeters, R. D., and Stolarski, R. S.: Anomalously low ozone over the Arctic, Geophys. Res. Lett., 24, 2689-2692, 1997.

Polvani, L. M., Waugh, D. W., Correa, G. J. P., and Son, S.-W.: Stratospheric Ozone Depletion: The Main Driver of Twentieth-Century Atmospheric Circulation Changes in the Southern Hemisphere, J. Clim., 24, 795-812, doi:10.1175/2010JCLI3772.1, 2011.

Portmann, R. W. and Solomon, S.: Indirect radiative forcing of the ozone layer during the 21 st century, Geophys. Res. Lett., 34, L02813, doi:10.1029/2006GL028252, 2007.

Purich, A. and Son, S.-W.: Impact of Antarctic Ozone Depletion and Recovery on Southern Hemisphere Precipitation, Evaporation, and Extreme Changes, J. Clim., 25, 3145-3154, doi:10.1175/JCLI-D-11-00383.1, 2012.

Randel, W. J. and Thompson, A. M.: Interannual variability and trends in tropical ozone derived from SAGE II satellite data and SHADOZ ozonesondes, J. Geophys. Res., 116, D07303, doi:10.1029/2010JD015195, 2011.

Randel, W. J. and Wu, F.: A stratospheric ozone profile data set for 1979-2005: Variability, trends, and comparisons with column ozone data, J. Geophys. Res., 112, D06313, doi:10.1029/2006JD007339, 2007.

Reinsel, G. C., Weatherhead, E. C., Tiao, G. C., Miller, A. J., Nagatani, R. M., Wuebbles, D. J., and Flynn, L. E.: On detection of turnaround and recovery in trend for ozone, J. Geophys. Res., 107, 4078, doi:10.1029/2001JD000500, 2002.

Rosenfield, J. E., Considine, D. B., Meade, P. E., Bacmeister, J. T., Jackman, C. H., and Schoeberl, M. R.: Stratospheric effects of Mount Pinatubo aerosol studied with a coupled two-dimensional model, J. Geophys. Res., 102, 3649-3670, 1997.

Solomon, S.: Stratospheric ozone depletion: A review of concepts and history, Rev. Geophys., 37, 275-316, 1999.

Solomon, S., Portmann, R. W., Garcia, R. R., Randel, W. J., Wu, F., Nagatani, R., Gleason, J., Thomason, L., Poole, L. R., and McCormick, M. P.: Ozone depletion at mid-latitudes: Coupling of volcanic aerosols and temperature variability to anthropogenic chlorine, Geophys. Res. Lett., 25, 1871-1874, 1998.

Solomon, S., Portmann, R. W., Sasaki, T., Hofmann, D. J., and Thompson, D. W. J.: Four decades of ozonesonde measurements over Antarctica, J. Geophys. Res., 110, D21311, doi:10.1029/2005JD005917, 2005.

Solomon, S., Young, P. J., and Hassler, B.: Uncertainties in the evolution of stratospheric ozone and implications for recent temperature changes in the tropical lower stratosphere, Geophys. Res. Lett., 39, L17706, doi:10.1029/2012GL052723, 2012.

Son, S.-W., Tandon, N. F., Polvani, L. M., and Waugh, D. W.: Ozone hole and Southern Hemisphere climate change, Geophys. Res. Lett., 36, L15705, doi:10.1029/2009GL038671, 2009.

Steinbrecht, W., Claude, H., Schoenenborn, F., McDermid, I. S., Leblanc, T., Godin, S., Song, T., Swart, D. P. J, Meijer, Y. J., Bodeker, G. E., Connor, B. J., Kaempfer, N., Hocke, K., Calisesi, Y., Schneider, N., de la Noe, J., Parrish, A. D., Boyd, I. S., Bruehl, C., Steil, B., Giorgetta, M. A., Manzini, E., Thomason, L. W., Zawodny, J. M., McCormick, M. P., Russell, J. M., Bhartia, P. K., Stolarski, R. S., and Hollandsworth-Frith, S. M.: Long-term evolution of upper stratospheric ozone at selected stations of the Network for the Detection of Stratospheric Change (NDSC), J. Geophys. Res., 111, D10308, doi:10.1029/2005JD006454, 2006.

Stolarski, R. S. and Frith, S. M.: Search for evidence of trend slowdown in the long-term TOMS/SBUV total ozone data record: the importance of instrument drift uncertainty, Atmos. Chem. Phys., 6, 4057-4065, doi:10.5194/acp-6-4057-2006, 2006.

Taylor, K. E., Stouffer, R. J., and Meehl G. A.: An Overview of CMIP5 and the Experiment Design, Bull. Am. Meteorol. Soc., 93, 485-498, 2012.

Telford, P., Braesicke, P., Morgenstern, O., and Pyle, J.: Reassessment of causes of ozone column variability following the eruption of Mount Pinatubo using a nudged CCM, Atmos. Chem. Phys., 9, 4251-4260, doi:10.5194/acp-9-4251-2009, 2009.

Wang, H. J., Cunnold, D. M., Thomason, L. W., Zawodny, J. M., and Bodeker, G. E.: Assessment of SAGE version 6. 1 ozone data quality, J. Geophys. Res., 107, 4691, doi:10.1029/2002JD002418, 2002.

WMO (World Meteorological Organization): Scientific Assessment of Ozone Depletion: 1998, Global Ozone Research and Monitor- 
ing Project - Report No. 44, Geneva, Switzerland, 1999.

WMO (World Meteorological Organization): Scientific Assessment of Ozone Depletion: 2002, Global Ozone Research and Monitoring Project - Report No. 47, Geneva, Switzerland, 2003.
WMO (World Meteorological Organization): Scientific Assessment of Ozone Depletion: 2010, Global Ozone Research and Monitoring Project - Report No. 52, Geneva, Switzerland, 2011. 